\title{
miR-210 is overexpressed in late stages of lung cancer and mediates mitochondrial alterations associated with modulation of HIF-1 activity
}

\author{
M-P Puisségur ${ }^{1,2,7}$, NM Mazure ${ }^{2,3}$, T Bertero ${ }^{1,2,8}$, L Pradelli $^{2,4}$, S Grosso $^{1,2}$, K Robbe-Sermesant $^{1,2}$, T Maurin $^{1,2,9,}$, K Lebrigand $^{1,2}$, \\ B Cardinaud ${ }^{1,2,10}$, V Hofman ${ }^{2,4}$, S Fourre ${ }^{1,2}$, V Magnone ${ }^{1,2}$, JE Ricci ${ }^{2,5}$, J Pouysségur ${ }^{2,3}$, P Gounon ${ }^{2,6}$, P Hofman $^{2,4}$, P Barbry ${ }^{\star, 1,2}$ \\ and $B$ Mari ${ }^{*, 1,2}$
}

Following the identification of a set of hypoxia-regulated microRNAs (miRNAs), recent studies have highlighted the importance of miR-210 and of its transcriptional regulation by the transcription factor hypoxia-inducible factor-1 (HIF-1). We report here that miR-210 is overexpressed at late stages of non-small cell lung cancer. Expression of miR-210 in lung adenocarcinoma A549 cells caused an alteration of cell viability associated with induction of caspase-3/7 activity. miR-210 induced a loss of mitochondrial membrane potential and the apparition of an aberrant mitochondrial phenotype. The expression profiling of cells overexpressing miR-210 revealed a specific signature characterized by enrichment for transcripts related to 'cell death' and 'mitochondrial dysfunction', including several subunits of the electron transport chain (ETC) complexes I and II. The transcript coding for one of these ETC components, SDHD, subunit D of succinate dehydrogenase complex (SDH), was validated as a bona fide miR-210 target. Moreover, SDHD knockdown mimicked miR-210-mediated mitochondrial alterations. Finally, miR-210-dependent targeting of SDHD was able to activate HIF-1, in line with previous studies linking loss-of-function SDH mutations to HIF-1 activation. miR-210 can thus regulate mitochondrial function by targeting key ETC component genes with important consequences on cell metabolism, survival and modulation of HIF-1 activity. These observations help explain contradictory data regarding miR-210 expression and its putative function in solid tumors.

Cell Death and Differentiation (2011) 18, 465-478; doi:10.1038/cdd.2010.119; published online 1 October 2010

Despite therapeutic improvements, prognosis of lung cancer is poor. Recent technical developments have focused on identifying specific gene expression signatures associated with tumor staging and patient prognosis to improve prognosis and therapy. ${ }^{1}$ Interestingly, microRNAs (miRNAs) tumor expression appears to be more accurate in determining the classification of cancer subtypes than classical mRNA expression profiles. ${ }^{2}$ These findings supported the concept of a specific miRNAs signature in solid tumors. ${ }^{3}$ Indeed, a growing number of miRNAs, such as those of the let-7 and miR-34 families, or the cluster miR-17-92 have been demonstrated to target genes that have an important role in lung carcinogenesis. $^{4}$

Although much progress concerning our understanding of miRNA function has been made, the identification of their targets still remains a limiting and difficult step. ${ }^{5}$ In the current molecular framework, mature miRNA, charged into a complex called miRNA-induced silencing complex (miRISC), which contains proteins of the Argonaute family, interact with complementary site(s), often located in the $3^{\prime}$-untranslated region (UTR) of a target mRNA. The current paradigm states that the interaction between the miRNA and its targets stems from a short stretch of six to eight nucleotides located at $5^{\prime}$ of the miRNA, termed the 'seed sequence'. ${ }^{6}$ miRISC complexes can relocate target mRNAs to specialized compartments, the processing bodies, where translation blockade or mRNA decay occur. Destabilization of mRNA induced by miRNA is substantiated by many studies. Combined with computational predictions, measurement of expression profiles for mRNAs represents

\footnotetext{
${ }^{1}$ Institut de Pharmacologie Moléculaire et Cellulaire, CNRS UMR6097, Sophia Antipolis, France; ${ }^{2}$ University of Nice Sophia-Antipolis, Nice, France; ${ }^{3} \mathrm{CNRS}$ UMR 6543 , Centre Antoine Lacassagne, Nice, France; ${ }^{4}$ ERI21/EA 4319, Laboratory of Clinical and Experimental Pathology and Human Biobank Unit, University Hospital Centre of Nice, Nice, France; ${ }^{5}$ Inserm, U895, Centre Méditerranéen de Médecine Moléculaire (C3M), Nice, France and ${ }^{6}$ Centre Commun de Microscopie Appliquée, Université de Nice-Sophia Antipolis, Nice, France

${ }^{*}$ Corresponding authors: P Barbry and B Mari, Institut de Pharmacologie Moléculaire et Cellulaire, CNRS UMR6097, 660, route des lucioles, F06560 Sophia Antipolis, France. Tel: + 3349395 7793; Fax: + 3349395 7794; E-mails: direction@ipmc.cnrs.fr or mari@ unice.fr

${ }^{7}$ Current address: INSERM U563, Centre de Physiopathologie de Toulouse-Purpan, Toulouse 31300, France

${ }^{8}$ Current address: INSERM U634, 28, Avenue de Valombrose, NICE 06107, France

${ }^{9}$ Current address: Memorial Sloan Kettering Cancer Center Rockefeller Laboratories, New York, NY 10065, USA

${ }^{10}$ Current address: INSERM U876, ESTBB, Université Bordeaux2, 146 rue Léo Saignat, Bordeaux 33076, France

Keywords: microRNA; non-small cell lung cancer; electron transport chain complex; hypoxia; apoptosis

Abbreviations: $\Delta \psi \mathrm{m}$, mitochondrial membrane potential; ETC, electron transport chain; HIF-1, hypoxia-inducible factor-1; HRE, hypoxia-responsive element; LNA, locked nucleic acid; miRISC, miRNA-induced silencing complex; miRNA, microRNA; NDUFA4, NADH dehydrogenase (ubiquinone) 1 alpha subcomplex, 4; NSCLCs, non-small cell lung carcinomas; PHD, HIF prolyl hydroxylase domain proteins; SDH, succinate dehydrogenase; SDHD, succinate dehydrogenase complex, subunit D; UTR, untranslated region; VHL, von Hippel-Lindau; XTT, 2, 3-bis(2-methoxy-4-nitro-5-sulfophenyl)-2H-tetrazolium-5-carboxanilide

Received 17.3.10; revised 12.8.10; accepted 16.8.10; Edited by B Zhivotovsky; published online 01.10 .10
} 
a powerful approach to identify functional miRNA-target relationships. ${ }^{7-9}$

We analyzed here the expression of miRNAs in a panel of biopsies of human non-small cell lung carcinomas (NSCLCs) and found that miR-210 was preferentially detected in latestage tumors. Recent studies have identified miR-210 among a set of hypoxia-regulated miRNAs and demonstrated the direct regulatory role of hypoxia-inducible factor-1 alpha (HIF-1 $\alpha$ ) in its transcription. ${ }^{10-12}$ Contradictory data however exist concerning the regulation and roles of miR-210 during cancer progression. miR-210 appears to be overexpressed in most solid tumors ${ }^{10,12-15}$ but absent in ovarian carcinoma. ${ }^{11}$ Furthermore, it has been shown that depending on the tissue type or cellular model, miR-210 was able to either promote entry into the cell cycle ${ }^{15}$ and to inhibit apoptosis ${ }^{16,17}$ or rather to repress tumor initiation. ${ }^{12}$ Several miR-210 targets have been investigated more specifically in the context of cancer, including cell-cycle regulator $E 2 F 3,{ }^{11}$ homeobox proteins (HOXA1, HOXA9), ${ }^{12}$ the myc antagnonist $M N T^{15}$ and the Iron Sulfur Cluster Assembly Proteins ISCU1/2, ${ }^{18}$ which are involved in many cellular processes such as heme biosynthesis and iron metabolism.

In this study, we provide evidence that miR-210 targets specific mitochondrial components with consequences on the regulation of cell death and survival and the modulation of HIF-1 activity.

\section{Results}

miR-210 is highly expressed at a late stage of lung cancers. miRNA expression was analyzed in 20 pairs of human NSCLC (i.e., pathological versus matched control tissues from the same patient, clinical characteristics listed in Supplementary Table S1) using methods described elsewhere. ${ }^{9,19}$ We identified 33 miRNAs of interest, 13 being common with the study of Yanaihara et al. ${ }^{20}$ (Supplementary Table S2). Figure 1a shows a heat map where the columns represent these 20 pairs of miRNA samples (tumor versus control) split into three groups according to their pathological tumor node and metastasis staging and where the rows correspond to the selection of these 33 miRNAs supplemented with 13 additional miRNAs previously described for this pathology, such as members of the let-7 and the miR-34 families. We also looked at individual miRNAs, the expression of which would differ during disease progression. We found three miRNAs with such a profile: miR-31, miR-210 and miR-451. Although miR-21, a well-known oncogenic miRNA present in most epithelial malignancies, was already found overexpressed at an early stage, higher expression of miR-210 and miR-31, and lower expression of miR-451 was usually associated with late stages of the disease (Figure 1a). We then focused our attention on one of these candidates, the HIF-1-regulated miR-210, based on previous reports suggesting a strong association between hypoxia and poor outcome in NSCLC. ${ }^{21,22}$

miR-210 expression correlates with a hypoxic signature in NSCLC and is upregulated by hypoxia in vitro. To compare miR-210 expression with a hypoxic signature, we first established the mRNA expression profiles of a subset of 13 biopsies from our initial NSCLC samples. The expression values of transcripts corresponding to a highly prognostic hypoxia signature (consisting of a small number of topranked hypoxic genes, including VEGFA, SLC2A1 and $P G A M 1)$ derived from a large meta-analysis of multiple cancers including lung cancer ${ }^{23}$ was used to set up a hypoxic index. The miR-210 levels in tumors showed positive correlation to this hypoxic index (Figure $1 \mathrm{~b}$ and Supplementary Table S3). Finally, using TaqMan quantitative (q)RT-PCR, miR-210 was significantly induced in A549 cells under hypoxic condition (Figure 1c), and this hypoxic induction was dependent on HIF- $1 \alpha$ but not HIF- $2 \alpha$ (Supplementary Figure S1) as previously reported in other models. ${ }^{12,24}$

miR-210 alters cell viability and enhances caspase-3/7 activity in $\mathbf{A 5 4 9}$ cells in normoxia. Giannakakis et al., ${ }^{11}$ using several bioinformatic predictions of miRNA targets, reported that miR-210 can target the transcript coding for the E2F family protein E2F3. Interestingly, E2F3 has also been identified as a target for the p53-regulated miR-34a. ${ }^{25}$ As miR-34a was also found slightly upregulated in some patients (Figure 1a), we compared the effect of miR-210 with miR-34a and an siRNA against E2F3 (si-E2F3) on E2F3 expression. miR-210 transfection led to a strong decrease in E2F3 protein expression (Figure 2a). A luciferase reporter assay with the E2F3 $3^{\prime}$ UTR fused to luciferase showed that miR-210 directly targets E2F3 (Figure 2b). We then compared ectopic expression of miR-210, miR-34a and siE2F3 on A549 cell viability and proliferation using the 2,3-bis(2methoxy-4-nitro-5-sulfophenyl)-2H-tetrazolium-5-carboxanilide (XTT) cell proliferation assay. After a transfection with miR-210 and si-E2F3, the number of A549 cells decreased over 5 days compared with the control (miR-Neg and si-Neg) (Figure 2c). Meanwhile, A549 cells transfected with miR-34a escaped inhibition after 3 days. Interestingly, caspase-3/7 activity assays revealed significant induction of apoptosis in A549 cells by miR-210 but not by si-E2F3 or miR-34a (Figure $2 \mathrm{~d}$ ).

Identification of miR-210 targets by mRNA profiling of A549 cells overexpressing miR-210. The influence of miR-210, miR-34a and si-E2F3 on transcript levels was investigated with human pangenomic arrays. ${ }^{26}$ Ectopic expression of miR-210 and miR-34a induced very different patterns of modulations (Figure 3a; see Supplementary Table S4 for the complete list of miR-210 deregulated transcripts). Moreover, a large number of changes induced by si-E2F3 were shared with miR-34a but not with miR-210 (Figure 3a, group 2), confirming that miR-210 acts probably through a distinct mechanism. A functional annotation of the different signature patterns with the Ingenuity Pathway software (Ingenuity Systems, Redwood City, CA, USA) was then performed. Although there was an important overlap for 'molecular functions' terms such as 'Cell Death', 'Cellular Growth and Proliferation' or 'Cell Cycle' between miR-210, miR-34a and si-E2F3 (Supplementary Table S5), we found some 'canonical pathways' specific to one or the other experimental conditions (Supplementary Table S6). As expected, the most significant pathway associated with miR-34 was 'p53 signalling' $\left(P=3.7 \times 10^{-7}\right)$. The score of 

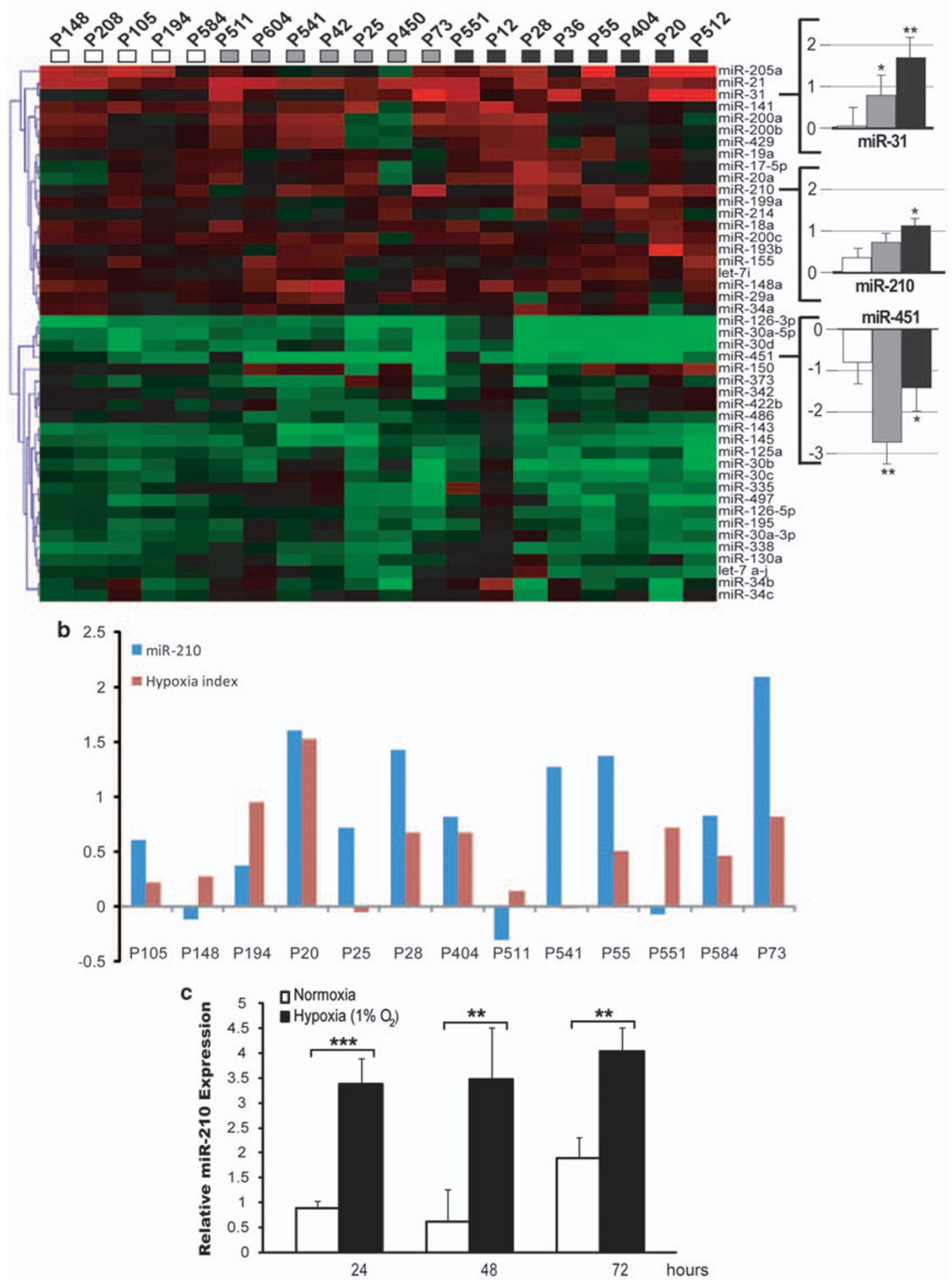

Figure 1 Overexpression of miR-210 in NSCLC is linked to hypoxia induction in tumors. (a) Unsupervised hierarchical clustering analysis of 42 miRNAs in 20 NSCLC samples. Distance was measured using the Manhattan distance on the matrix of the log2 (ratio) and classification was performed using a complete agglomeration method. Histograms on the right of the panel represent miR-210, miR-31 and miR-451 modulation in three different stages of the disease. (b) Expression of miR-210 and the hypoxic index in 13 NSCLC samples. Histograms represent the log2 ratio of tumor versus normal adjacent tissues for miR-210 and for a hypoxic index corresponding to the average value of the 15 top-ranked genes (see Supplementary Table S3 for the list of the transcripts) of the common hypoxia metagene identified by Buffa et al. ${ }^{23}$ Similar results were obtained with the full list of this common hypoxia signature. (c) miR-210 expression was monitored by qPCR on RNA from A549 cells with or without exposure to $1 \% \mathrm{O}_{2}$ at indicated times. Mean \pm S.E.M. is representative of three independent experiments carried out in triplicate. ${ }^{* \star} P<0.0005,{ }^{* \star} P<0.005,{ }^{*} P<0.05$ 
a kDa miR-Neg miR-210 miR-34a si-Neg si-E2F3
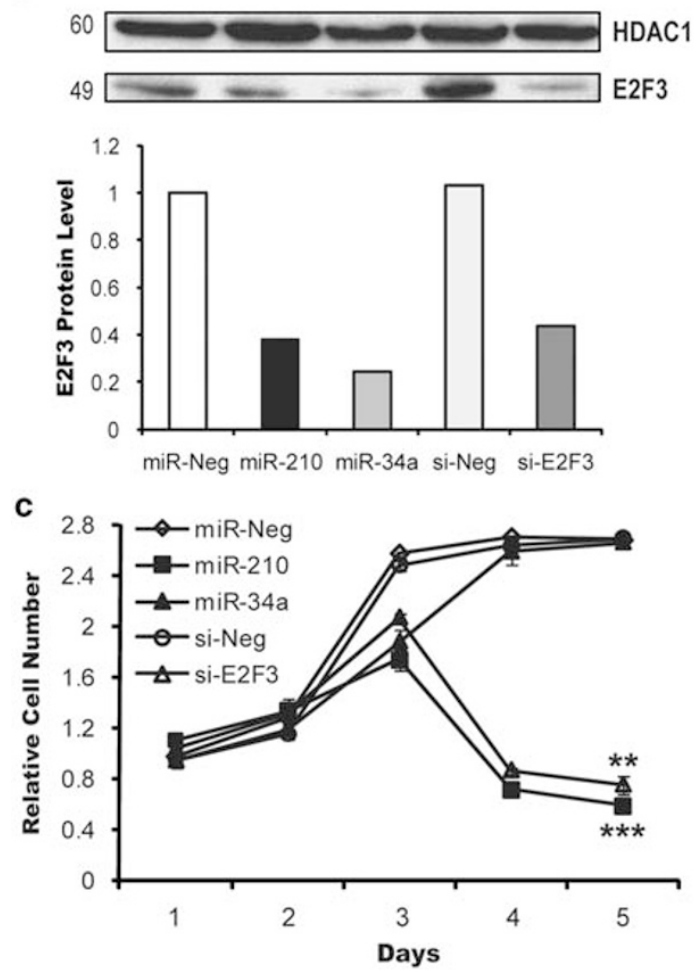
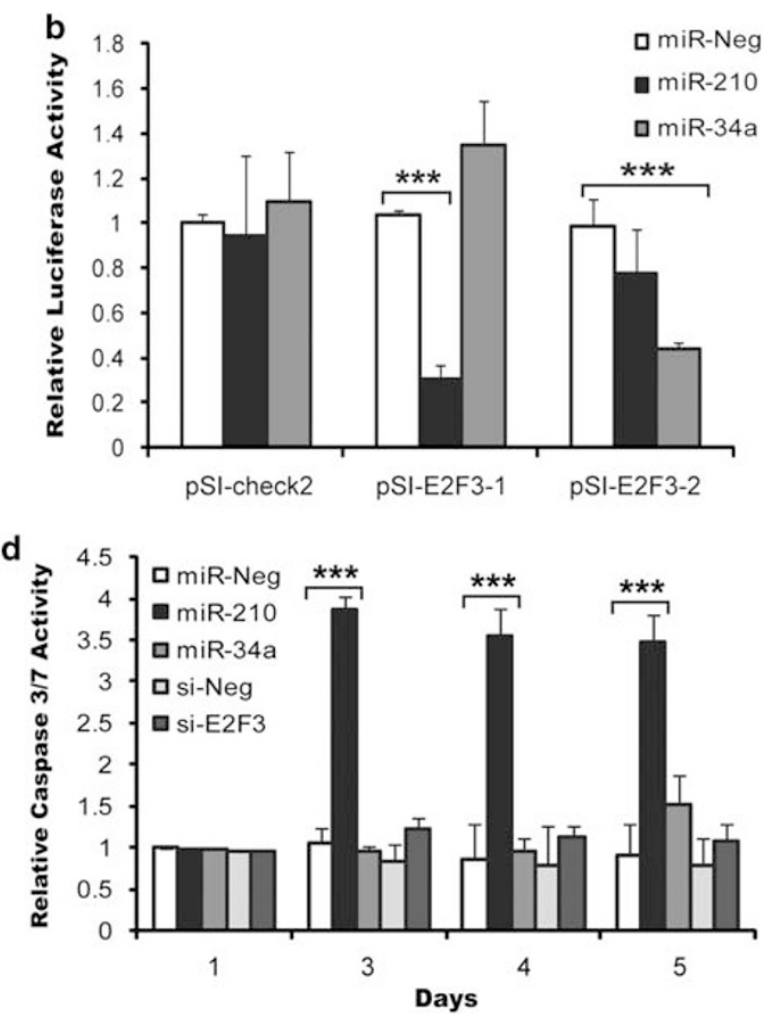

Figure 2 miR-210 targets E2F3 and alters A549 cell viability. (a) A549 cells were transfected with $10 \mathrm{nM}$ pre-miR-210, premiR-34a, pre-miR-Neg, si-Neg or si-E2F3 as a positive control. E2F3 protein levels were determined by western blotting on day 2 after transfection. HDAC1 expression was used as a loading control. (b) A549 cells were co-transfected with $10 \mathrm{nM}$ pre-miR-Neg, pre-miR-210 or pre-miR-34a and different $\mathrm{pSI}$-Check-2 constructs. Cells were harvested 2 days after transfection and the luciferase activities analyzed. All Renilla luciferase activities were normalized to the firefly luciferase activity. pSI-E2F3-1 and pSI-E2F3-2 correspond to distinct fragments of the E2F3 $3^{\prime}$ UTR containing putative miR-210 and miR-34a putative binding sites, respectively; pSI-check2 was used as an empty vector control. (c) The XTT cell viability assay was performed on days 1-5 after transfection of A549 cells with pre-miR-Neg, pre-miR-210, pre-miR-34a, si-Neg or si-E2F3. (d) The caspase-3/7 assay was carried out on A549 cells transfected under the same conditions as in (c). Results correspond to three independent experiments performed in duplicate. ${ }^{* \star *} P<0.0005$, ${ }^{* \star} P<0.005$

several metabolic pathways altered by the presence of miR-210 was explained by its effects on several genes encoding aldehyde dehydrogenases, but we also noticed enrichment for a pathway related to 'Mitochondria Dysfunction' (Supplementary Table S6). This particularly interesting latter observation was explained by downregulation of several members of complexes I and II of the electron transport chain (ETC) (Supplementary Figure S2).

We next looked for putative miR-210 direct targets in the population of downregulated transcripts using our web tool 'MicrotopTable' (Figures 3b-d). ${ }^{9}$ They indicate a specific overrepresentation of miR-210- and miR-34a-predicted targets in the transcripts downregulated after heterologous expression of both miRNAs. We then focussed our analysis on 38 transcripts containing miR-210 complementary hexamers in their $3^{\prime}$ UTR that show the largest inhibition of expression (Table 1). When this set of genes was functionally annotated, we found an enrichment for mitochondrial components (Supplementary Table S7), explained in part by the presence of two members of ETC complexes: $\mathrm{NADH}$ dehydrogenase (ubiquinone) 1 alpha subcomplex, 4 (NDUFA4), a subunit of ETC complex I, and succinate dehydrogenase complex, subunit $D(S D H D)$, a subunit of the ETC complex II.
miR-210 directly targets NDUFA4 and SDHD and induces mitochondrial dysfunctions. To test whether NDUFA4 and $S D H D$ were directly targeted by miR-210, we fused the $3^{\prime}$ UTR of SDHD and NDUFA4 to a luciferase reporter. Co-transfection with a synthetic pre-miR-210 significantly decreased the luciferase activity compared with a premiR-Neg, strongly suggesting that both genes are miR-210 targets (Figure 4a). In the absence of specific antibodies against these two proteins, we performed western blot analysis on other subunits of these two ETC complexes (Figure 4b). miR-210 decreased the level of expression of the $70 \mathrm{kDa}$ ETC complex II subunit (SDHA) but it had no efffect on the $39 \mathrm{kDa}$ ETC complex I subunit (NDUFA9) and the $20 \mathrm{kDa}$ ETC complex I (NDUFS7). Finally, the activity of ETC complex II was directly measured on cell lysates of A549 cells, $72 \mathrm{~h}$ following transfection with a pre-miR-Neg or pre-miR-210. miR-210 specifically decreased succinate dehydrogenase (SDH) complex II activity compared with the miR-Neg control (Figure 4c). Electron microscopy performed on miR-210-transfected A549 cells revealed mitochondrial structural alterations (Figure 4d): although the morphology of mitochondria in pre-miR-Neg transfected A549 cells appeared as a tubular network with normal internal membrane invaginations, miR-210-expressing cells 
a

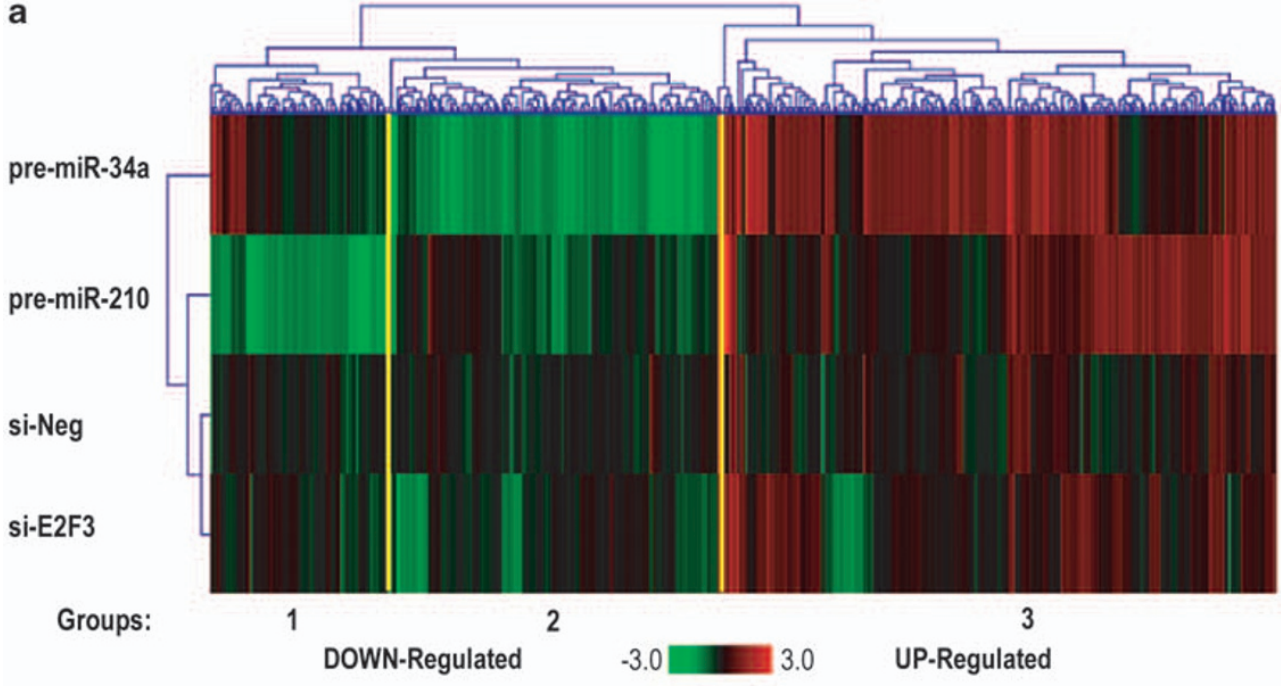

b

pre-miR-210

C

pre-miR-34a
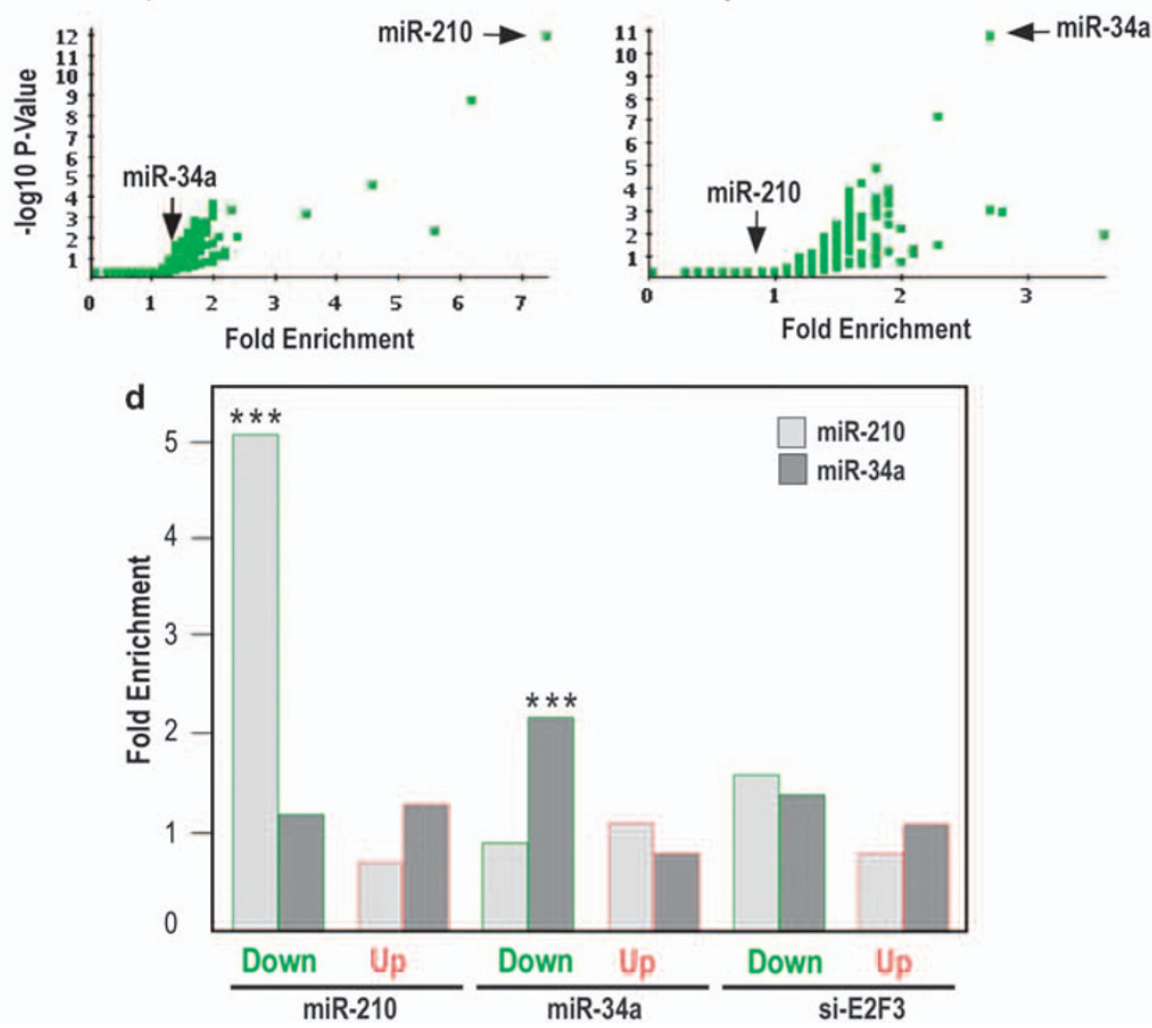

Figure 3 Identification of miR-210 candidate targets using a transcriptomic approach. A549 cells were transfected with pre-miR-Neg, pre-miR-210, pre-miR-34a, as well as siE2F3 or a control siRNA (si-Neg) $(n=2)$. RNA samples were harvested at $48 \mathrm{~h}$ after transfection and expression profiles were determined with pangenomic arrays. (a) Heatmap comparing the normalized log2 of the ratios between the signal in the different conditions and the pre-miR-Neg signal at $48 \mathrm{~h}$ after transfection. (b and $\mathbf{c}$ ) Overrepresentation of miR-210 (b) and miR-34a (c) predicted targets according to TargetScan algorithm following transfection with pre-miR-210 and pre-miR-34a, respectively. Representation of miRNA predicted targets in the set of up- or downregulated genes was compared with the set of all expressed genes. For each miRNA, a fold enrichment value (horizontal axis) and an associated $P$-value (vertical axis) were calculated. (d) Histogram representing the enrichment for the presence of seed complementary hexamers in the $3^{\prime} \mathrm{UTR}$ of down- or upregulated transcripts following transfection with pre-miR-210, pre-miR-34a and si-E2F3. ${ }^{* \star *} P<0.0005$

showed enlarged mitochondria with a modified organization of cristae. These phenotypic modifications were indeed associated with mitochondrial dysfunctions, as evidenced by an altered mitochondrial membrane potential $(\Delta \psi \mathrm{m})$ (Supplementary Figure S3A).
The direct effect of miR-210 on SDHD was then assessed with an siRNA-targeting SDHD (si-SDHD). Silencing of SDHD with two different siRNAs mimicked the enlarged mitochondrial phenotype observed with miR-210 (Figure 5a and Supplementary Figure S3B). Both si-SDHD and miR-210 
Table 1 List of the miR-210-predicted targets downregulated following miR-210 overexpression in A549 cells

\begin{tabular}{|c|c|c|c|c|c|c|}
\hline Symbol & ID & $\begin{array}{l}\text { GenBank } \\
\text { ID }\end{array}$ & $\begin{array}{l}\text { Average } \\
\text { expression }\end{array}$ & LogFC & $\begin{array}{l}\text { Accession } \\
\text { number }\end{array}$ & Description \\
\hline ABCC3 & 102419 & 8714 & 13.2 & -1.6 & NM_020038 & $\begin{array}{l}\text { Homo sapiens ATP-binding cassette, subfamily C (CFTR/ } \\
\text { MRP), member } 3 \text { (ABCC3), transcript variant MRP3B, mRNA }\end{array}$ \\
\hline ABL1 & 10499 & 25 & 10.9 & -1.3 & NM_005157 & $\begin{array}{l}\text { H. sapiens c-abl oncogene } 1 \text {, receptor tyrosine kinase (ABL1), } \\
\text { transcript variant a, mRNA }\end{array}$ \\
\hline ALDH5A1 & 63840 & 7915 & 9.3 & -1.7 & NM_170740 & $\begin{array}{l}\text { H. sapiens aldehyde dehydrogenase } 5 \text { family, member } \mathrm{A} 1 \\
\text { (ALDH5A1), nuclear gene encoding mitochondrial protein, } \\
\text { transcript variant } 1 \text {, mRNA }\end{array}$ \\
\hline C22orf9 & 120469 & 23313 & 9.2 & -1.3 & NM_015264 & $\begin{array}{l}\text { H. sapiens chromosome } 22 \text { open reading frame } 9 \text { (C22orf9), } \\
\text { transcript variant } 1, \text { mRNA }\end{array}$ \\
\hline CDCA7L & 34411 & 55536 & 9.43 & -1.13 & NM_018719 & $\begin{array}{l}\text { H. sapiens cell division cycle-associated } 7 \text {-like (CDCA7L), } \\
\text { transcript variant } 1, \text { mRNA }\end{array}$ \\
\hline $\begin{array}{l}\text { COL4A2 } \\
\text { DCBLD1 }\end{array}$ & $\begin{array}{l}94674 \\
72084\end{array}$ & $\begin{array}{r}1284 \\
285761\end{array}$ & $\begin{array}{l}11.9 \\
11.4\end{array}$ & $\begin{array}{l}-2.5 \\
-1.6\end{array}$ & $\begin{array}{l}\text { NM_001846 } \\
\text { AK055462 }\end{array}$ & $\begin{array}{l}\text { H. sapiens collagen, type IV, alpha } 2 \text { (COL4A2), mRNA } \\
\text { H. sapiens CDNA FLJ30900 fis, clone FEBRA2005752 }\end{array}$ \\
\hline DDOST & 9043 & 1650 & 11.9 & -1.6 & NM_005216 & $\begin{array}{l}\text { H. sapiens dolichyl-diphosphooligosaccharide-protein } \\
\text { glycosyltransferase (DDOST), mRNA }\end{array}$ \\
\hline DHFR & 90261 & 1719 & 12.4 & -1.2 & NM_000791 & H. sapiens dihydrofolate reductase (DHFR), mRNA \\
\hline DKFZp434H1419 & 77126 & 150967 & 8.8 & -1.1 & AL137534 & $\begin{array}{l}\text { H. sapiens mRNA; cDNA DKFZp434H1419 (from clone } \\
\text { DKFZp434H1419); partial cds }\end{array}$ \\
\hline $\begin{array}{l}\text { EHD2 } \\
\text { ELOF1 }\end{array}$ & $\begin{array}{l}22648 \\
46850\end{array}$ & $\begin{array}{l}30846 \\
84337\end{array}$ & $\begin{array}{l}11 \\
9.3\end{array}$ & $\begin{array}{l}-1.4 \\
-1.2\end{array}$ & $\begin{array}{l}\text { NM_014601 } \\
\text { NM_032377 }\end{array}$ & $\begin{array}{l}\text { H. sapiens EH-domain containing } 2 \text { (EHD2), mRNA } \\
\text { H. sapiens elongation factor } 1 \text { homolog (Saccharomyces } \\
\text { cerevisiae) (ELOF1), mRNA }\end{array}$ \\
\hline EPB41L1 & 174127 & 2036 & 10 & -1.2 & NM_012156 & $\begin{array}{l}\text { H. sapiens erythrocyte membrane protein band } 4.1 \text {-like } 1 \\
\text { (EPB41L1), transcript variant } 1 \text {, mRNA }\end{array}$ \\
\hline FAM102A & 69086 & 399665 & 10.4 & -1.3 & NM_203305 & $\begin{array}{l}\text { H. sapiens family with sequence similarity } 102 \text {, member A } \\
\text { (FAM102A), transcript variant } 2 \text {, mRNA }\end{array}$ \\
\hline FAM3C & 116003 & 10447 & 9.8 & -1.1 & NM_014888 & $\begin{array}{l}\text { H. sapiens family with sequence similarity } 3 \text {, member C } \\
\text { (FAM3C), transcript variant } 1 \text {, mRNA }\end{array}$ \\
\hline FKBP9 & 14807 & 11328 & 11.1 & -1.1 & NM_007270 & H. sapiens FK506 binding protein $9,63 \mathrm{kDa}$ (FKBP9), mRNA \\
\hline GDE1 & 31188 & 51573 & 9.37 & -1.12 & NM_016641 & $\begin{array}{l}\text { H. sapiens glycerophosphodiester phosphodiesterase } 1 \\
\text { (GDE1), mRNA }\end{array}$ \\
\hline GIT2 & 104909 & 9815 & 9.9 & -1.6 & NM_057169 & $\begin{array}{l}\text { H. sapiens G-protein-coupled receptor kinase interacting } \\
\text { ArfGAP } 2 \text { (GIT2), transcript variant 1, mRNA }\end{array}$ \\
\hline H2AFY & 167895 & 9555 & 12.4 & -1.3 & NM_001040158 & $\begin{array}{l}\text { H. sapiens } \mathrm{H} 2 \mathrm{~A} \text { histone family, member } \mathrm{Y}(\mathrm{H} 2 \mathrm{AFY}) \text {, transcript } \\
\text { variant } 4 \text {, mRNA }\end{array}$ \\
\hline $\begin{array}{l}\text { HOXA1 } \\
\text { INHBB }\end{array}$ & $\begin{array}{l}11017 \\
93581\end{array}$ & $\begin{array}{l}3198 \\
3625\end{array}$ & $\begin{array}{l}9.6 \\
8.7\end{array}$ & $\begin{array}{l}-1.1 \\
-1.4\end{array}$ & $\begin{array}{l}\text { NM_005522 } \\
\text { NM_002193 }\end{array}$ & $\begin{array}{l}\text { H. sapiens homeobox A1 (HOXA1), transcript variant } 1 \text {, mRNA } \\
\text { H. sapiens inhibin, beta B (INHBB), mRNA }\end{array}$ \\
\hline LASP1 & 14926 & 3927 & 13.3 & -2.1 & NM_006148 & H. sapiens LIM and SH3 protein 1 (LASP1), mRNA \\
\hline LHFP9776 & 9776 & 10186 & 9.7 & -1.4 & NM_005780 & H. sapiens lipoma HMGIC fusion partner (LHFP), mRNA \\
\hline MRPL36 & 48403 & 64979 & 12.3 & -1.4 & NM_032479 & $\begin{array}{l}\text { H. sapiens mitochondrial ribosomal protein L36 (MRPL36), } \\
\text { nuclear gene encoding mitochondrial protein, mRNA }\end{array}$ \\
\hline NDUFA4 & 93962 & 4697 & 14.8 & -2.3 & NM_002489 & $\begin{array}{l}\text { H. sapiens NADH dehydrogenase (ubiquinone) } 1 \text { alpha } \\
\text { subcomplex, } 4,9 \mathrm{kDa} \text { (NDUFA4), nuclear gene encoding } \\
\text { mitochondrial protein, mRNA }\end{array}$ \\
\hline NUP210 & 42162 & 23225 & 11.6 & -1.3 & NM_024923 & H. sapiens nucleoporin $210 \mathrm{kDa}$ (NUP210), mRNA \\
\hline PDXK & 37342 & 8566 & & & & $\begin{array}{l}\text { H. sapiens pyridoxal (pyridoxine, vitamin B6) kinase (PDXK), } \\
\text { mRNA }\end{array}$ \\
\hline $\begin{array}{l}\text { PSAP } \\
\text { SCARA3 }\end{array}$ & $\begin{array}{r}132543 \\
24194\end{array}$ & $\begin{array}{r}5660 \\
51435\end{array}$ & $\begin{array}{r}11.7 \\
9.4\end{array}$ & $\begin{array}{l}-1.5 \\
-1.9\end{array}$ & $\begin{array}{l}\text { NM_002778 } \\
\text { NM_016240 }\end{array}$ & $\begin{array}{l}\text { H. sapiens prosaposin (PSAP), transcript variant } 1 \text {, mRNA } \\
\text { H. sapiens scavenger receptor class } A \text {, member } 3 \text { (SCARA3), } \\
\text { transcript variant } 1 \text {, mRNA }\end{array}$ \\
\hline $\begin{array}{l}\text { SDF2 } \\
\text { SDHD }\end{array}$ & $\begin{array}{l}17519 \\
99293\end{array}$ & $\begin{array}{l}6388 \\
6392\end{array}$ & $\begin{array}{l}10 \\
10.8\end{array}$ & $\begin{array}{l}-1.4 \\
-1.4\end{array}$ & $\begin{array}{l}\text { NM_006923 } \\
\text { NM_003002 }\end{array}$ & $\begin{array}{l}\text { H. sapiens stromal cell-derived factor } 2 \text { (SDF2), mRNA } \\
H \text {. sapiens succinate dehydrogenase complex, subunit } \mathrm{D} \text {, } \\
\text { integral membrane protein (SDHD), nuclear gene encoding } \\
\text { mitochondrial protein, mRNA }\end{array}$ \\
\hline SH3BGRL & 97796 & 6451 & 11.1 & -2 & NM_003022 & $\begin{array}{l}\text { H. sapiens SH3 domain binding glutamic acid-rich protein-like } \\
\text { (SH3BGRL), mRNA }\end{array}$ \\
\hline SIPA1L3 & 1390 & 23094 & 10 & -1.4 & NM_015073 & $\begin{array}{l}\text { H. sapiens signal-induced proliferation-associated 1-like } 3 \\
\text { (SIPA1L3), mRNA }\end{array}$ \\
\hline STAT6 & 97969 & 6778 & 10.6 & -1.1 & NM_003153 & $\begin{array}{l}\text { H. sapiens signal transducer and activator of transcription } 6 \text {, } \\
\text { interleukin-4-induced (STAT6), mRNA }\end{array}$ \\
\hline TERF2IP & 36068 & 54386 & 11.6 & -1.4 & NM_018975 & $\begin{array}{l}\text { H. sapiens telomeric repeat binding factor } 2 \text {, interacting protein } \\
\text { (TERF2IP), mRNA }\end{array}$ \\
\hline TMEM80 & 79504 & 283232 & 11.5 & -1.5 & NM_001042463 & $\begin{array}{l}\text { H. sapiens transmembrane protein } 80 \text { (TMEM80), transcript } \\
\text { variant } 2 \text {, mRNA }\end{array}$ \\
\hline $\begin{array}{l}\text { TNPO3 } \\
\text { VAMP7 }\end{array}$ & $\begin{array}{l}18486 \\
12699\end{array}$ & $\begin{array}{r}23534 \\
6845\end{array}$ & $\begin{array}{l}10.5 \\
10.70\end{array}$ & $\begin{array}{l}-1.4 \\
-1.66\end{array}$ & $\begin{array}{l}\text { NM_012470 } \\
\text { NM_005638 }\end{array}$ & $\begin{array}{l}\text { H. sapiens transportin } 3 \text { (TNPO3), mRNA } \\
\text { H. sapiens vesicle-associated membrane protein } 7 \text { (VAMP7), } \\
\text { transcript variant } 1 \text {, mRNA }\end{array}$ \\
\hline
\end{tabular}

The 38 transcripts containing at least one complementary sequence to the 'seed 2-7' of miR-210 in their 3'UTR and strongly repressed following miR-210 transfection are listed. Cutoffs for selection are equal to 8.0 for the $\log _{2}$ (signal), to -1 for the $\log _{2}$ (ratio), and to 0.001 for the adjusted $P$-value. Logarithm (base 2 ) of the ratio of $\mathrm{miR}-210 / \mathrm{miR}-\mathrm{Neg}$ is represented. ID corresponds to RNG oligo IDs that gives access to transcripts and probes annotations through our information system Mediante (http://www.microarray.fr:8080/merge/index) 
a

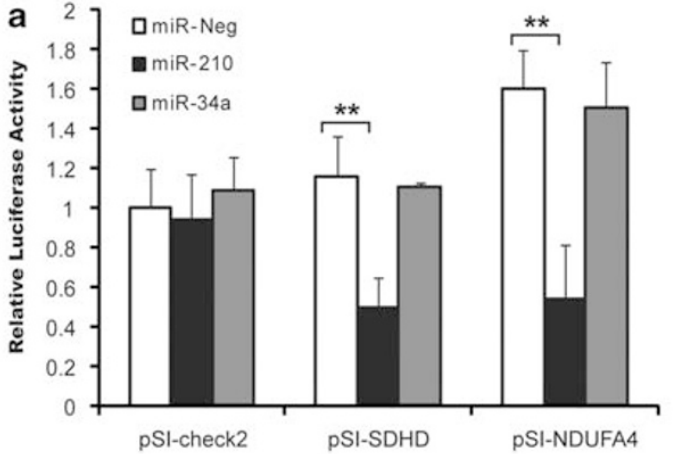

b

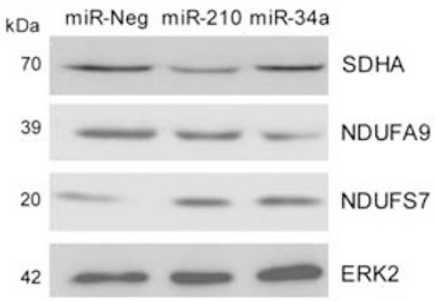

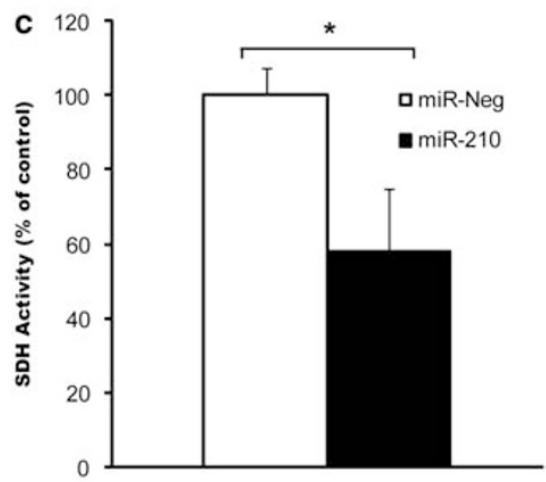

d miR-Neg

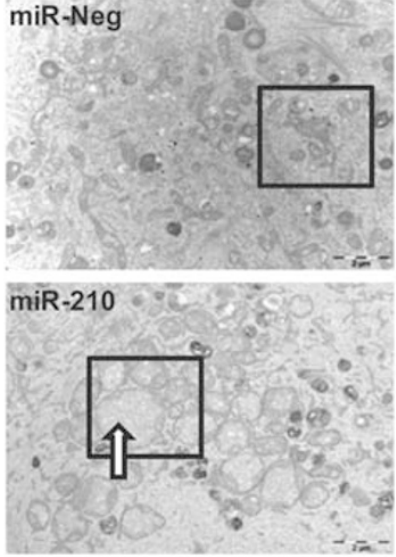

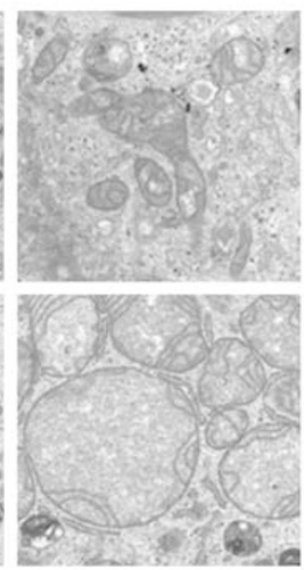

Figure 4 miR-210 targets SDHD and induces mitochondrial dysfunction. (a) Direct targeting of SDHD and NDUFA4 by miR-210 in vitro. A549 cells were co-transfected with $10 \mathrm{nM}$ of pre-miR-Neg, pre-miR-210 or pre-miR-34a with pSI-Check-2 constructs containing the 3'UTR of SDHD (pSI-SDHD) or NDUFA4 (pSI-NDUFA4). Cells were harvested 2 days after transfection and luciferase activities were analyzed. (b) Effect of miR-210 expression on endogenous members of ETC complexes I and II. The A549 cell line was transfected with $10 \mathrm{nM}$ pre-miR-Neg, pre-miR-210 or pre-miR-34a. SDHA, NDUFA9 and NDUFS7 protein levels were determined by western blotting on day 2 after transfection. Total ERK2 was used as a loading control. (c) Complex II activity was performed on A549 cells on day 3 after transfection with pre-miR-Neg or pre-miR-210. (d) Electron micrographs of the ultrastructure of mitochondria of A549 cells transfected with miR-Neg or miR-210. All data are representative of three independent experiments. ${ }^{*} P<0.005,{ }^{*} P<0.05$

induced a significant decrease in metabolically active cells 4 and 5 days following the treatment (Figure $5 b$ ). Finally, the activity of caspase- 3 and -7 was also increased by miR-210 and by si-SDHD, although to a lower extent (Figure $5 \mathrm{c}$ ).

Effects of miR-210 on cell survival and alteration in the phenotype of mitochondria in hypoxia. As alteration in mitochondrial function can lead to different consequences on cell death and survival in normoxia or hypoxia, we next performed clonogenic assays in which miR-210 was overexpressed or knocked down under normoxic or hypoxic conditions. As expected, transfection of a locked nucleic acid (LNA) inhibitor of miR-210 (LNA-210) in hypoxic A549 cells reduced miR-210 expression to the low basal normoxic level when compared with an LNA-159s control inhibitor (Figure 6a). Although transfection with a synthetic pre-miR210 reduced clonogenic potential in normoxia (Figure $6 \mathrm{~b}$, left), in agreement with our previous data on apoptosis and cell proliferation (Figures 2 and 4), treatment with LNA-210 resulted in decreased clonogenic survival of A549 cells following $72 \mathrm{~h}$ of hypoxia (Figure $6 \mathrm{~b}$, right). We also quantified in the same experimental settings, alterations in the mitochondrial phenotype as visualized by electron microscopy, which showed that LNA-210 could indeed significantly increase the average number of cristae under hypoxic conditions (Figure 6c).

miR-210 positively regulates HIF-1 $\alpha$ activity. As mutations in $\mathrm{SDH}$ subunits have been shown to activate HIF-1, ${ }^{27,28}$ we next wondered whether miR-210 had a positive effect on HIF-1 activity. As controls, we also evaluated the effect of miR-34a as well as those of si-E2F3 and si-SDHD. We measured their impact on several luciferase reporter vectors downstream to a minimal promoter containing either E2F, p53 or a hypoxia-responsive element (HRE) (Supplementary Figure S4). As expected, both miR-210 and miR-34a duplexes, as well as si-E2F3, induced a decrease in E2F reporter activity (Supplementary Figure S4A), whereas miR-34a duplex alone could increase p53 reporter activity (Supplementary Figure S4B). Of note, prolonged overexpression of the miR-210 duplex as well as silencing of SDHD resulted into a modest but significant increase of HRE luciferase reporter activity, suggesting that miR-210mediated $S D H D$ targeting leads to HIF-1 $\alpha$ stabilization under normoxic conditions (Supplementary Figure S4C). We next evaluated the level of expression and activity of HIF- $1 \alpha$ in experiments in which miR-210 was overexpressed or knocked down under normoxic or hypoxic conditions (Figure 7). Overexpression of $\mathrm{miR}-210$ in normoxic 
a

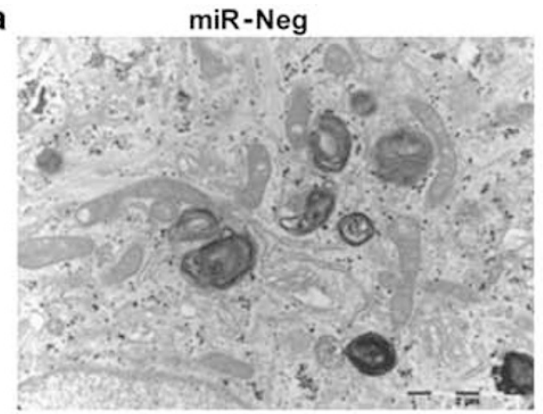

si-Neg

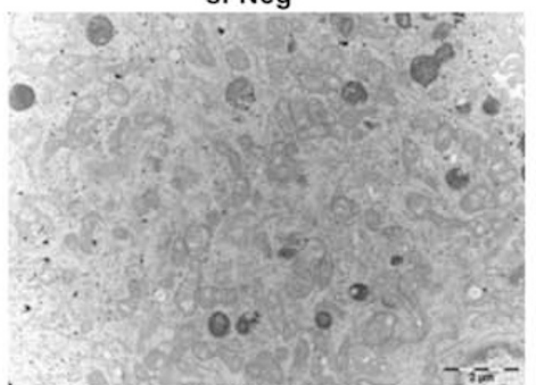

si-SDHD 1

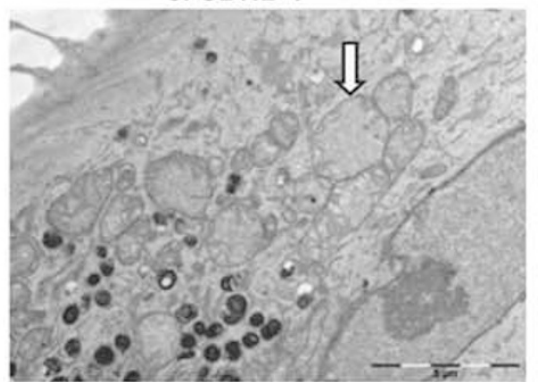

b 1.4
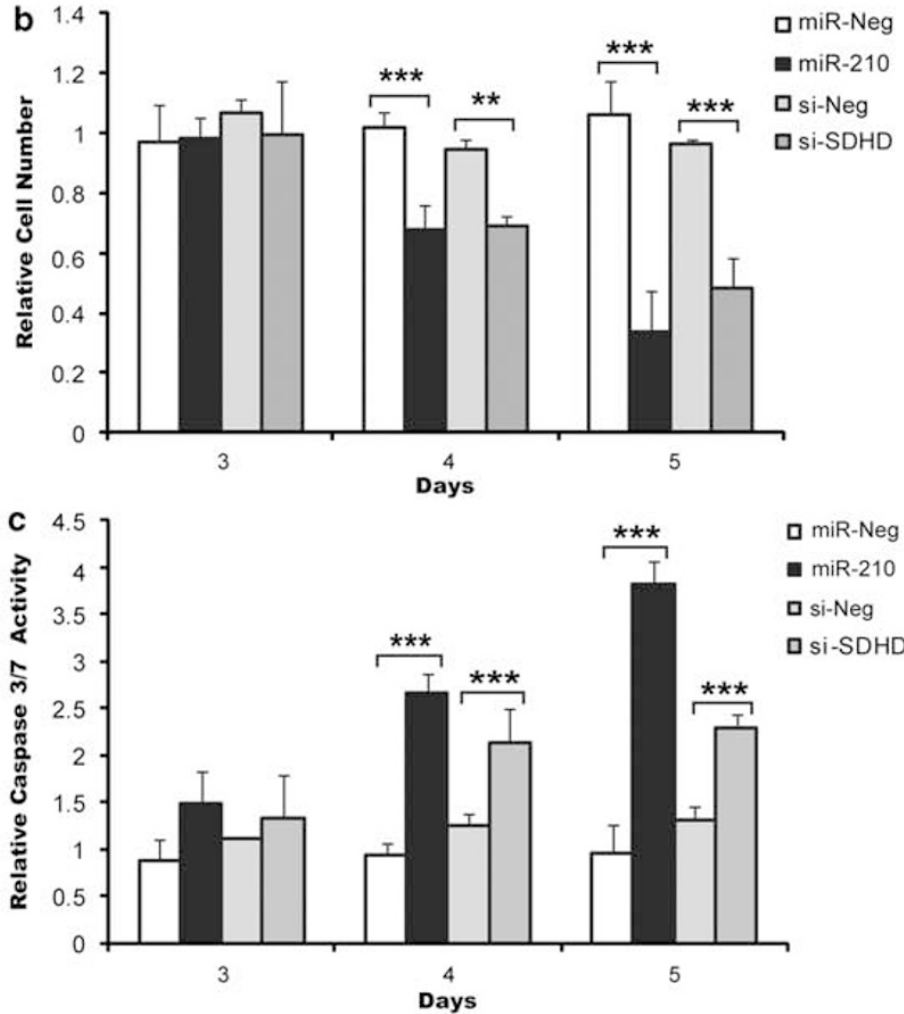

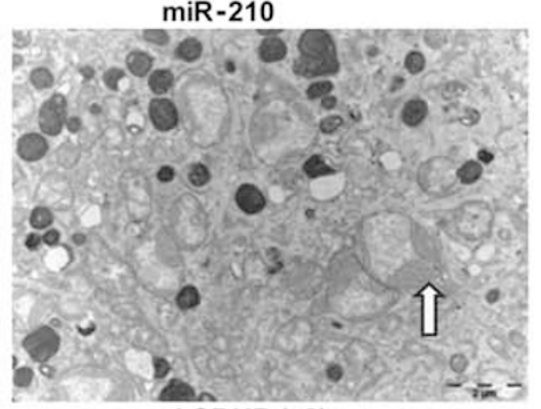

si-SDHD (x2)

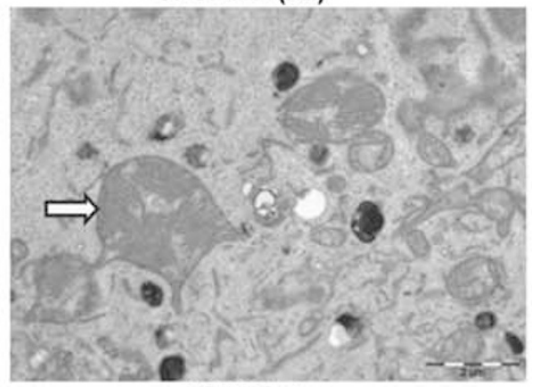

si-SDHD 2

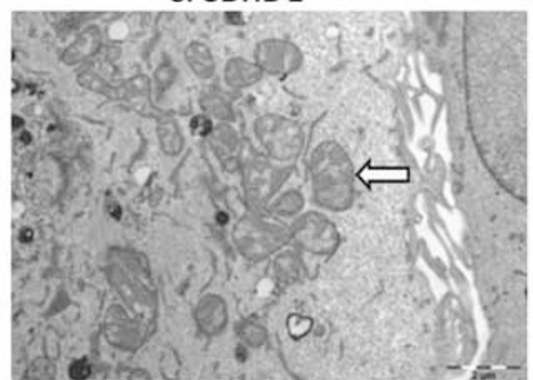

口 miR-Neg

miR-210

口 si-Neg 

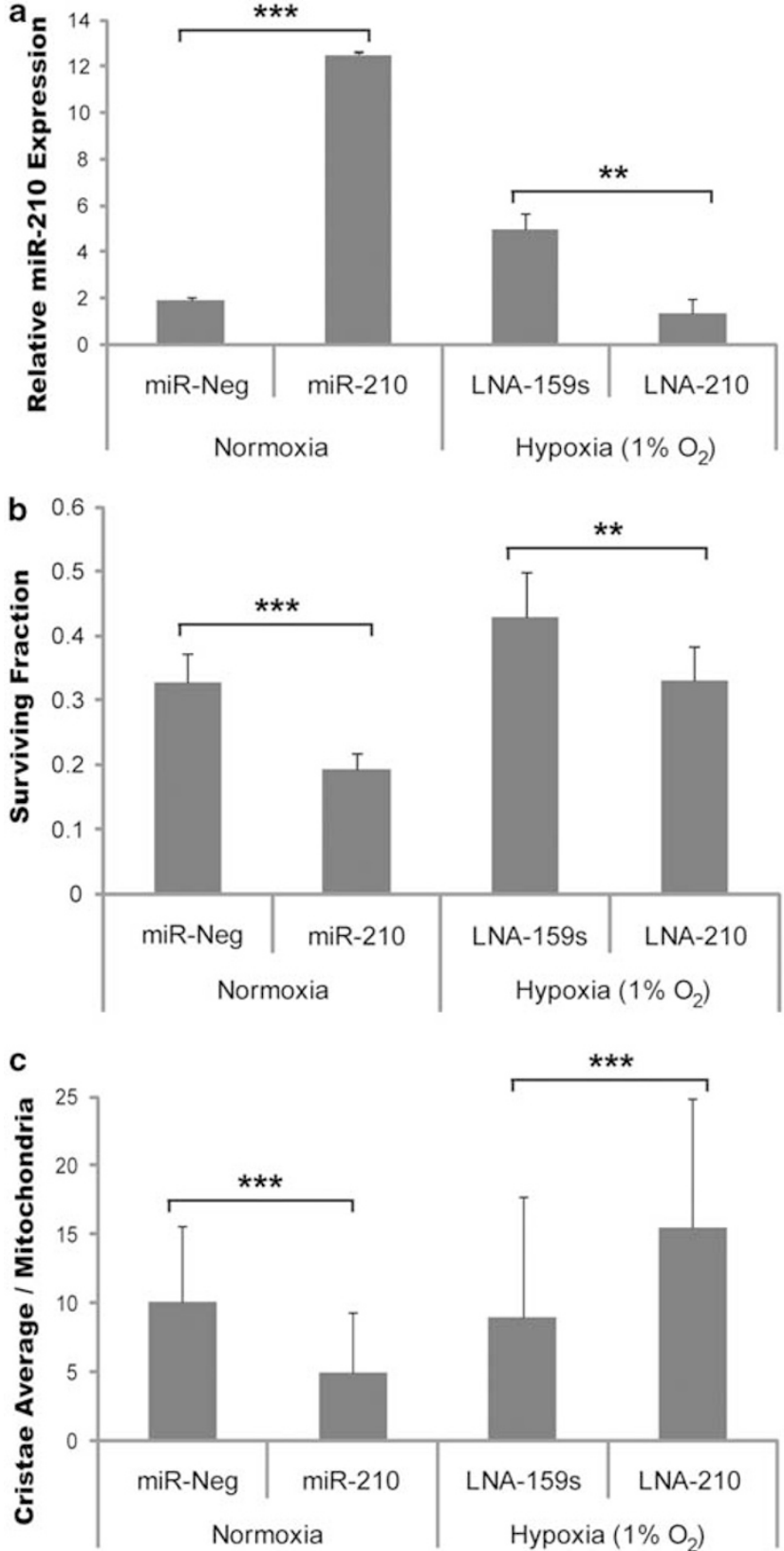

Figure 6 miR-210 inhibition decreases cell survival and affects the phenotype of mitochondria in hypoxia. A549 cells were transfected with either pre-miR-Neg, pre-miR-210, a control anti-miR-159s LNA or anti-miR-210, before $72-96 \mathrm{~h}$ exposure to normoxia or $1 \% \mathrm{O}_{2}$. (a) miR-210 expression was monitored by qPCR on RNA from A549 cells with or without exposure to $1 \% \mathrm{O}_{2}(72 \mathrm{~h})$. (b) Following exposure to normoxia or hypoxia $(72 \mathrm{~h}$ ), cells were re-plated (100 and 500 cells per well) and incubated during 11 days. Colonies were then fixed, stained, and the surviving fractions were calculated based upon the plating efficiency. (c) Quantification of the average number of cristae in cells fixed in situ $96 \mathrm{~h}$ following exposure to normoxia or hypoxia. Mean \pm S.E.M. is representative of two independent experiments carried out in triplicate. ${ }^{* \star *} P<0.0005,{ }^{* \star} P<0.005$ conditions only led to a slight increase in HIF- $1 \alpha$ levels $72 \mathrm{~h}$ after transfection (Figure 7a), in agreement with the HRE luciferase reporter data (Supplementary Figure S4C). Importantly, inhibition of miR-210 in hypoxia decreased HIF- $1 \alpha$ proteins levels after $48-72 \mathrm{~h}$ of hypoxia (Figure 7a). After $48 \mathrm{~h}$ of hypoxia, HIF-1 activity, as assessed after co-transfection of a HRE luciferase reporter, was reduced by LNA-210, and returned to basal values observed during normoxia (Figure $7 \mathrm{~b}$ ). Finally, the LNA-210 also reduced hypoxia-mediated lactate production to a similar extent as an siRNA against HIF- $1 \alpha$ (Figure 7c).

\section{Discussion}

The global miRNA profile reported here (Figure 1) is in good agreement with previous reports, ${ }^{3,20}$ showing upregulation of miR-21, miR-155, miR-146a and miR-210, and repression of miR-125a, miR-143, miR-145 and miR-218. Stratification of the samples according to their stages revealed distinct levels of expression for miR-31, miR-210 and miR-451 among these groups. The low level of expression of miR-210 during early stages (1A, T1N0) and its progressive increase with growth and invasion of tumor cells fits well with previous reports showing a correlation between the well-characterized HIF-target carbonic anhydrase IX, hypoxia and advanced $\mathrm{T}$ stage. ${ }^{21,22} \mathrm{~A}$ good correlation was also noted between miR-210 expression and hypoxic markers in our cohort of patients, confirming that miR-210 expression was likely driven by hypoxia in vivo, as previously shown in other solid tumors. ${ }^{10,12}$

In an effort to better understand the function of miR-210 in lung tumor cells, we have first analyzed the consequences of miR-210 overexpression in A459 adenocarcinoma cells cultured under normoxic condition. Induction of apoptosis by miR-210 is consistent with very recent reports indicating that miR-210 represses the growth of tumor xenograft from head, neck and pancreatic cancer cells ${ }^{12}$ and increases apoptosis in pulmonary arterial endothelial cells (HPAECs) in vitro. ${ }^{18}$ While we confirmed that the transcript coding for E2F3, a key protein in the cell cycle, is a functional target of miR-210, ${ }^{11}$ we also found that miR-210 induced cell death associated with activation of caspases, whereas E2F3 siRNA did not. Indeed, E2F3 silencing and miR-210 overexpressions led to very distinctive expression patterns, thus suggesting that the effect of miR-210-induced cell death was rather mediated by targeting other transcripts.

Among the set of transcripts that were downregulated after ectopic expression of miR-210, we restricted our work to a group of 38 transcripts containing miR-210 complementary hexamers in their $3^{\prime} U T R$ and possessing the strongest modulation factors and statistical $P$-values. Eight transcripts of this list have already been identified in others cell types using other experimental approaches. ${ }^{12,15}$ Moreover, additional miR-210 predicted targets described elsewhere, ${ }^{12,15,29}$

Figure 5 SiRNAs directed against SDHD induce modifications in mitochondrial shape and apoptosis. (a) Mitochondrial ultrastructure in A549 cells transfected with pre-miR-Neg, pre-miR-210, si-Neg or two different si-SDHD alone or together and fixed in situ at 4 days after transfection. miR-210 and si-SDHD strongly modified mitochondrial structure (arrow). (b) XTT cell proliferation and (c) caspase-3/7 assays were performed on A549 cells transfected with pre-miR-Neg, pre-miR-210, si-Neg or si-SDHD. All data are representative of three independent experiments performed in triplicate. ${ }^{* \star *} P<0.0005,{ }^{* \star} P<0.005$ 

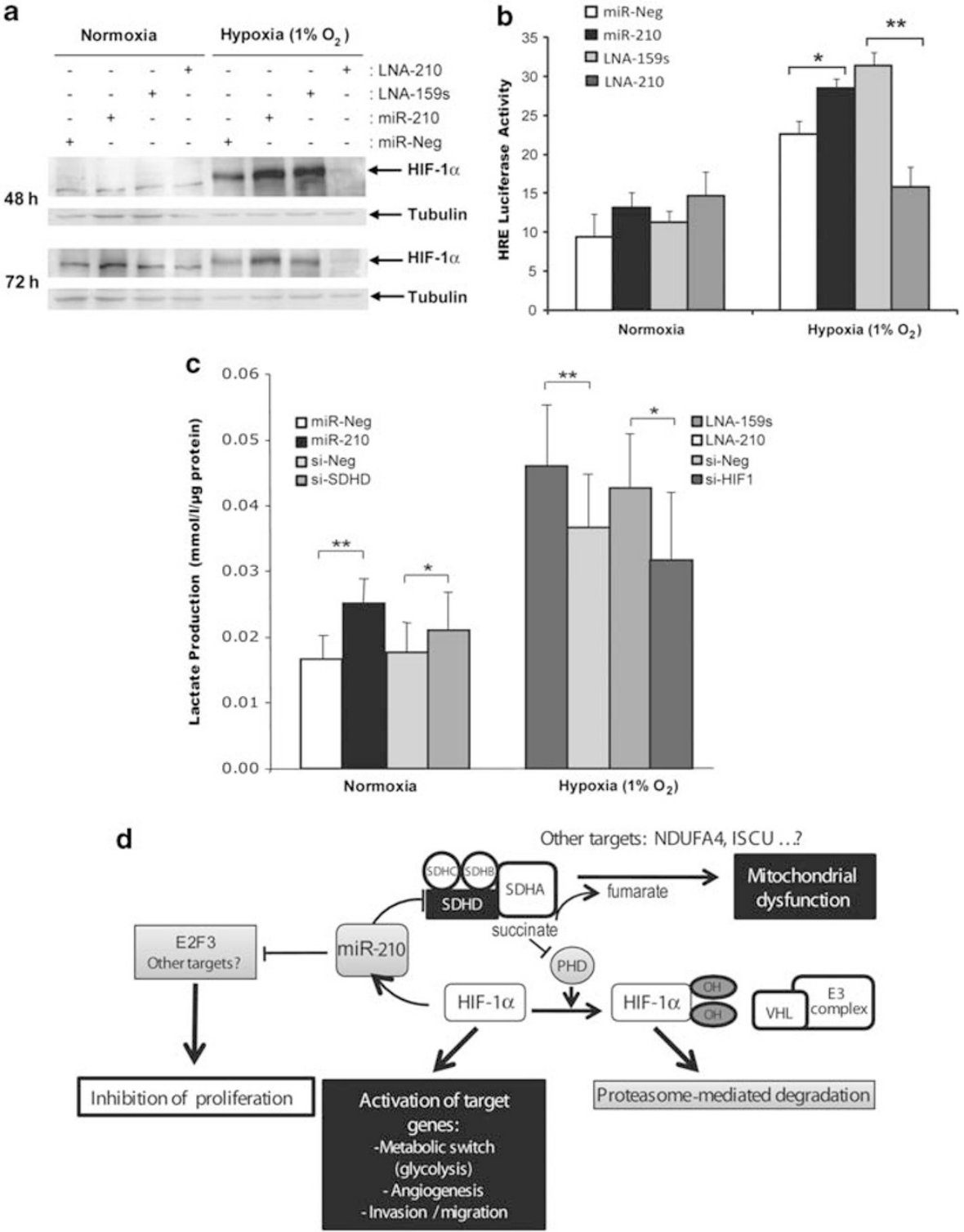

Figure 7 miR-210 inhibition reduces HIF activity in hypoxic A549 cells. A549 cells were transfected with either pre-miR-Neg, pre-miR-210, a control anti-miR-159s LNA or anti-miR-210 in normoxia or hypoxia $\left(1 \% \mathrm{O}_{2}\right)$ and incubated for $48-72 \mathrm{~h}$. (a) Protein levels of HIF- $1 \alpha$ and of the loading control $\alpha$-tubulin. (b) A549 cells were co-transfected with an HRE luciferase reporter and HIF activity was assessed using the dual luciferase reporter assay system at $48 \mathrm{~h}$ following transfection. Determinations were done in triplicate and the experiment was repeated three times. (c) The extracellular lactate concentration of transfected cells incubated in normoxia or hypoxia $1 \% \mathrm{O}_{2}$ for $48 \mathrm{~h}$ was normalized to cell protein for each condition. Mean \pm S.E.M. is representative of three independent experiments carried out in triplicate. (d) Proposed model for miR-210, SDHD and HIF-1 $\alpha$ inter-regulation. HIF-1 $\alpha$ upregulates miR-210, which in turn downregulates SDHD, leading to complex II dysfunction. High succinate levels resulting from loss of complex II could inhibit the PHD activity giving HIF-1 $\alpha$ stabilization. ${ }^{\star \star} P<0.005,{ }^{*} P<0.05$

including the recently validated gene ISCU, ${ }^{18}$ were also identified after relaxing the $\log _{2}$ ratio cutoff to -0.5 , comforting our methodological approach. It remains that the list of proposed miRNA targets always requires a direct validation by western blot analyses and/or reporter plasmid assays.

Functional annotations of the miR-210 overexpression experiments related miR-210 to 'Mitochondria Dysfunction', in line with the downregulation at mRNA level of several members of the complexes I and II of the ETC. We then focused on two components: one subunit of ETC complex I, NDUFA4, and one of the four subunits of complex II, SDHD.
Our model indicates that miR-210-mediated downregulation of these ETC components could participate in mitochondrial dysfunction. Electron microscopy experiments strongly support this hypothesis (Figures $4 d$ and $5 a$ ), showing enlarged mitochondria with a modified organization of cristae in miR-210-expressing cells. These phenotypic modifications were associated with a decrease in the $\Delta \psi \mathrm{m}$, consistent with our observation of an induction of apoptosis.

Although the direct validation of these two targets was handicapped by the absence of specific antibodies against NDUFA4 and SDHD, we used three complementary 
approaches: (i) 3'UTR luciferase constructs; (ii) western blotting of other subunits of these two complexes; and (iii) the activity of the two complexes. Although a NDUFA4 3'UTR luciferase construct displayed significant inhibition by miR-210, we did not detect any effect of miR-210 at the protein level on other components nor on the activity of ETC complex I. This contrasted with SDHD, the fourth subunit of mitochondrial complex II, and also SDH of the TCA cycle, for which decreased expression and activity were noticed. It has been shown that mutations in $\mathrm{SDH}$ subunits including SDHD were linked with cancer and, in particular, lead to the development of paragangliomas or pheocromocytomas. ${ }^{30}$ A known consequence of the functional loss of any of these subunits is a great reduction of the enzymatic activity of the whole complex associated with an unusual mitochondria phenotype. Accordingly, SDHD inhibition mimicked several miR-210-mediated cellular effects, including alteration of mitochondrial ultrastructure (Figure 5a), decrease of cell viability (Figure $5 b$ ) and activation of caspases (Figure $5 c$ ).

Our findings appear particularly interesting in the light of the report published during the preparation ${ }^{18}$ and revision ${ }^{24,31}$ of this paper, showing that miR-210 also targets the transcript coding for ISCU1/2. ISCU1/2 facilitate the assembly of ironsulfur clusters that are incorporated into enzymes involved in energy production, including mitochondrial respiratory complexes I, II and III. Chan et al. ${ }^{18}$ provided evidence that the lower levels of expression of ISCU1/2 mediated by miR-210 contribute to a decrease in the activity of the TCA cycle (through aconitase targeting) and the ETC (through complex I destabilization). Further studies will be necessary to dissect the relative importance of ISCU1/2 and SDHD on miR-210 function, but it is already tempting to speculate that some synergy exists between both mechanisms.

The regulation of these mitochondrial components by the miR-210 pathway appears to have contrasting consequences on the regulation of cell death and survival under normoxic or hypoxic conditions. Indeed, clonogenic assays performed in either condition revealed that although overexpression of miR-210 reduced clonogenic potential in normoxia, treatment with LNA-210 resulted in decreased clonogenic survival in hypoxia (Figure $6 \mathrm{~b}$ ). These apparently contradictory results highlight the complex processes involved in the regulation of mitochondrial respiration and energy production in the hypoxic cell. ${ }^{32}$ On the basis of this model, miR-210 overexpression in normoxia would create a mitochondrial dysfunction including a mismatch in electron transport that could lead notably to an increase in toxic reactive oxygen species as recently suggested ${ }^{24}$ and increased apoptosis as corroborated by our data (Figures $2 \mathrm{~d}, 5 \mathrm{~b}$ and $\mathrm{c}$ ). In contrast, during hypoxia, the miR-210-dependent repression of the ETC via SDHD, NDUFA4 or ISCU1/2 and other validated or yet unknown targets would be protective by participating in the homeostatic downregulation of mitochondrial respiration. Notably, these effects can be recapitulated in clonogenic assays (Figure 6b) and are in agreement with similar data published during the revision of this paper. ${ }^{24}$ Overall, these data strongly suggest that although miR-210 exerts a maladaptive role in normoxia, its induction following hypoxia would, in contrast, be protective, as suggested by other studies. ${ }^{17,18,33}$
As the respiratory chain also serves as an intracellular $\mathrm{O}_{2}$ sensor, miR-210-mediated targeting of SDHD is likely to have direct functional consequences on HIF- $1 \alpha$ activation. This molecular mechanism may have a role in the regulation of the phenomenon of increased glycolysis in tumors, known for decades as the 'Warburg effect'. ${ }^{34}$ The link between the loss of mitochondrial tumor suppressors and pseudo-hypoxia was indicated by several studies showing that $\mathrm{SDH}$ subunit mutations were linked with HIF-1 activation in highly vascularized tumors such as paragangliomas and pheochromocytomas. $^{35}$ Of note, microarray analysis of these SDH subunit-deficient tumors (including SDHD) revealed an HIF signature identical to that of a group of von Hippel-Lindau (VHL)-deficient tumors. ${ }^{28}$ The VHL tumor suppressor is a key mediator of HIF activity, mediating ubiquitination and subsequent proteasome-mediated degradation of HIF- $1 \alpha$ following its hydroxylation by HIF prolyl hydroxylase domain proteins (PHD1, 2 or 3 ) in normoxia. ${ }^{36}$ Importantly, it has been shown that feedback inhibition of PHDs by succinate, a product of PHDs, leads to HIF- $1 \alpha$ stabilization. ${ }^{37}$ Our findings showing that both miR-210 overexpression and SDHD silencing increase HRE luciferase activity are in perfect agreement with these data.

Moreover, another level of interplay has been proposed in which HIF-1 is also able to downregulate components of the mitochondrial complex II. ${ }^{28}$ Our findings suggest that miR-210 could explain this observation and be part of an autoregulatory loop, whereby HIF-1 contributes to attenuation of SDHD levels, leading to complex II inhibition, accumulation of succinate and resulting in blockade of $\mathrm{HIF}-1 \alpha$ degradation (Figure 7d). In agreement with this hypothesis, miR-210 inhibition reduced both the duration of HIF activation and lactate production in hypoxia (Figure $7 \mathrm{a}-\mathrm{c}$ ). The precise impact of the miR-210/SDHD interaction in a hypoxic environment on HIF activity remains to be studied in detail, as well as its consequences on mitochondria ultrastructure, function and cell death.

In conclusion, here we have identified $S D H D$ as a direct target of miR-210, thus revealing a positive-regulatory loop associating miR-210 and HIF-1 $\alpha$. Histological and functional evidences show that miR-210 exerts a major influence on mitochondrial function, cell survival and homeostasis. These data will now be further explored in light with other miR-210 targets to analyze its precise impact on hypoxia-related diseases including cancer.

\section{Materials and Methods}

Clinical samples. Twenty pairs of primary NSCLC and corresponding non-cancerous lung tissues were obtained from patients in Nice (France) and collected by the Tumor Biobank of the Nice Hospital (http:// www.biobank06.com/, agreement LPB04/LPB05). All patients signed an informed consent sheet for this study. Clinical and pathological data are described in Supplementary Table S1.

Cell culture. The lung adenocarcinoma A549 cell line was purchased from the American Type Culture Collection and grown in Dulbecco's modified Eagle medium supplemented with L-glutamine, penicillin, streptomycin and $10 \%$ heat-inactivated fetal calf serum (FCS) at $37^{\circ} \mathrm{C}$ in a humidified $5 \% \mathrm{CO}_{2}$ air atmosphere. A Bug-Box anaerobic workstation (Ruskinn Technology, Bridgend, UK) set at 1\% oxygen, $94 \%$ nitrogen and $5 \%$ carbon dioxide was used for hypoxic conditions. 
RNA isolation. Frozen tissue ( $\sim 50 \mathrm{mg}$ ) from clinical samples was pulverized in a stainless steel mortar and pestle. Total RNA was extracted from the samples with TRIzol solution (Invitrogen, Cergy Pontoise, France), and the integrity of RNA was assessed by using an Agilent BioAnalyser 2100 (Agilent, Massy, France, RIN above 6.5). RNA concentration was determined using the ND-1000 microspectrophotometer (NanoDrop Technologies, Wilmington, DE, USA). The miRvana miRNA isolation kit was used for isolation and enrichment of small RNA fractions (Ambion, Austin, TX, USA), according to the manufacturer's protocol.

QRT-PCR of mature miRNA. miR-210 expression was evaluated using TaqMan MicroRNA Assay (Applied Biosystems, Carlsbad, CA, USA) as specified in their protocol. Real-time qPCR was performed using GeneAmp Fast PCR Master Mix (Applied Biosystems) and Lightcycler 480 (Roche) real-time PCR machine. All reactions were performed in duplicate. Expression levels of mature miRNAs were evaluated using comparative CT method $\left(^{2-\Delta} \mathrm{CT}\right)$. Transcript levels of RNU6B were used as endogenous control.

Transfection. Chemically synthesized miRNA duplexes, called pre-miR-210, pre-miR-34a and control miRNA (pre-miR-Neg number 1), were purchased from Ambion; for miR-210 knockdown experiments, anti-miR-210 LNA and negative control anti-miR-159s LNA (miRCURY LNA knockdown probes) were ordered from Exiqon (Vedbaek, Denmark). SiRNAs directed against E2F3, SDHD and NDUFA4 were from Applied Biosystems. A549 cells were transfected at $50 \%$ confluency with Lipofectamin RNAi MAX (Invitrogen) and with pre-miRNA, siRNA or the LNA inhibitor at a final concentration of $10 \mathrm{nM}$.

Molecular constructs. Molecular constructs were made in pSI-CHECK-2 (Promega, Charbonnières-les-Bains, France) by cloning behind the Renilla luciferase in the Xhol and Notl restrictions sites, $3^{\prime} \mathrm{UTR}$ sequences from E2F3, NDUFA4 and SDHD mRNA and named as PSI-E2F3-1 (containing the miR-210binding site), pSI-E2F3-2 (containing the miR-34a-binding site), pSI-NDUFA4 and pSI-SDHD, respectively. A positive control for miR-210 was created by cloning a miR-210 complementary sequence in Xhol/Notl restriction sites in PSI-CHECK-2 (Promega) and named as pSI-miR-210.

hsa-E2F3-1/sense: 5'-ACTACTCGAGGTGTTGTCCCTTCCTACCTTCTT-3' hsa-E2F3-1/reverse: 5'-ATAAGAATGCGGCCGCGCACATTTTCTCACTTGCT GAC-3'

hsa-E2F3-2/sense: $5^{\prime}$-CCGCTCGAGGCTGCTATTAAAGCTCACACACGAA-3' hsa-E2F3-2/reverse: 5'-ATAAGAATGCGGCCGCACGAGTTGTCATGCACACA CTGAA-3'

hsa-SDHD/sense: $5^{\prime}$-GGTGGACAGCCTTCTTCTCTTAATC-3'

hsa-SDHD/reverse: $5^{\prime}$-CATAGAATACATTTTCACATTAGAGATTCCC- $3^{\prime}$

hsa-NDUFA4/sense: 5'-GAAATGTTTCACTATAACGCTGCTTTAG-3'

hsa-NDUFA4/reverse: 5'-GCCAGTGTCAGATGCTGGAG-3'

miRNA targets validation by luciferase assay. Co-transfection of $200 \mathrm{ng}$ pSI-CHECK-2 with $10 \mathrm{nM}$ of pre-miRNA was carried out in 96-well plates with Lipofectamine 2000 (Invitrogen). Transfection of the same combinations of plasmid and RNAs were repeated three times in HEK293 (data not shown) and A549 cells. The medium was replaced $8 \mathrm{~h}$ after transfection with fresh medium containing 10\% FCS and L-glutamine, and supplemented with penicillin and streptomycin. At $48 \mathrm{~h}$ after transfection, firefly and Renilla luciferase activities were measured using the Dual-Glo luciferase assay (Promega).

Cell proliferation assay. A549 cells were plated at $3 \times 10^{3}$ cells per well in 96-well plates with triplicate wells for each transfection. Cell proliferation was performed using the XTT colorimetric assay (Cell proliferation assay kit II, Roche). After 2-5 days of transfection with pre-miRNAs or siRNAs, $50 \mu \mathrm{l}$ of XTT labeling mixture was added to each well, and incubation was continued for $2 \mathrm{~h}$. Cell viability was assessed by measuring the absorbance at $490 \mathrm{~nm}$ using a microtiter plate (ELISA) reader.

Caspase-3/7 assay. The activation of executioner caspase- 3 and -7 in A549 cells was determined using the Caspase-Glo $3 / 7$ Assay kit (Promega) according to manufacturer's instructions. A549 cells were plated in triplicate in 96-well plates and transfected as described above. Luminescence was quantified after $1 \mathrm{~h}$ of incubation with the caspase substrate.
Western blot analysis. Cells were lysed in $1.5 \times$ Laemmli buffer and the protein concentration determined using the bicinchoninic acid assay. In the case of E2F3, nuclear extracts were made using the NE-PER kit (Pierce, Thermo Fisher Scientific, Brebières, France). In all, $40 \mu \mathrm{g}$ of protein of whole-cell extracts was resolved by SDS-PAGE and transferred onto a polyvinylidene fluoride membrane (Millipore, Billerica, MA, USA). Membranes were blocked in $5 \%$ non-fat milk in TN buffer ( $50 \mathrm{mM}$ Tris- $\mathrm{HCl}(\mathrm{pH} 7.4), 150 \mathrm{mM} \mathrm{NaCl})$ and incubated in the presence of the primary and then secondary antibodies in $5 \%$ non-fat milk in TN buffer. After washing in TN buffer containing $1 \%$ Triton-X100 and then in TN buffer, immunoreactive bands were visualized with the ECL system (Amersham Biosciences, Orsay, France). Antibodies to E2F3 (N-20), total ERK2 and $\alpha$-tubulin were purchased from Santa Cruz Biotechnology (Santa Cruz, CA, USA) to NDUFA9 and SDHA from Invitrogen and to HDAC1 from Neomarker (Fremont, CA, USA). The rabbit polyclonal anti-HIF-1 $\alpha$ antibody (antiserum 2087) has been reported previously. ${ }^{38}$

Transmission electronic microscopy. Cells were fixed in situ with $1.6 \%$ glutaraldehyde in $0.1 \mathrm{M}$ phosphate buffer at room temperature for at least $1 \mathrm{~h}$ and then conserved at $4^{\circ} \mathrm{C}$. Samples were rinsed in the same buffer then post-fixed with $1 \%$ osmium tetroxide and $1 \%$ potassium ferrocyanide in $0.1 \mathrm{M}$ cacodylate buffer for $1 \mathrm{~h}$ at room temperature enhance the staining of cytoplasmic membranes. Cells were rinsed with distilled water and embedded in epoxy resin. Embedded samples were then processed for thin sectioning and observed with a JEM1400 transmission electron microscope (Jeol, Tokyo, Japan) equipped with a Morada CCD camera (Olympus SIS, Rungis, France).

\section{Microarrays}

miRNA microarrays. The oligonucleotide sequences corresponding to 2054 mature miRNAs (including 409 Homo sapiens) found in the miRNA registry (Release $8.2^{39}$ ) are available on http://www.microarray.fr:8080/merge/index (follow the link to 'microRNA': platform referenced in GEO as GPL4717 and GPL4718). The experimental data and microarray design have been deposited in the NCBI Gene Expression Omnibus (GEO, http://www.ncbi.nlm.nih.gov/geo/) under serie GSE18692. The experimental design used a dye-swap approach, so that each human probe, printed eight times on the microarray was measured independently 16 times for each sample. Target preparation and array hybridization were performed as previously described. ${ }^{9,19}$

Expression microarrays. Pangenomic microarrays were printed using the human RNG/MRC oligonucleotide collection as previously described. ${ }^{26}$ RNA were labeled and hybridized as previously described. ${ }^{9}$ Two biological replicates were performed for each comparison. The experimental data and microarray design have been deposited in the NCBI Gene Expression Omnibus (GEO) (http:// www.ncbi.nlm.nih.gov/geo/) under serie GSE18694.

Statistical analysis. Normalization was performed using the Limma package available from Bioconductor (http://www.bioconductor.org). Intra- and inter-slide normalization was performed using the Print Tip Loess and the quantile methods, respectively. Means of ratios from all comparisons were calculated and $B$ test analysis was performed. Differentially expressed genes were selected using Benjamini-Hochberg correction of the $P$-value for multiple tests, based on a $P<0.01$.

Biological theme analysis. Data from expression microarrays were analyzed for enrichment in biological themes (Gene Ontology molecular function and biological process) and build biological networks built using Ingenuity Pathway Analysis software (http://www.ingenuity.com/) and Mediante (http://www. microarray.fr:8080/merge/index), ${ }^{40}$ an information system containing diverse information about our probes and data sets.

miR-210 targets analysis. MicroTopTable is an online java web tool (available at http://www.microarray.fr:8080/merge/index; follow the link to microRNA and Bioinformatic tools) that integrates DNA microarrays data to identify the potential implication of miRNAs on a specific biological system. ${ }^{9}$ Briefly, MicroTopTable ranks the transcripts into three categories ('Upregulated', 'Down regulated' and 'Nonmodulated'), according to thresholds for expression level and for differential expression. It then calculates the number of predicted targets for each miRNA, according to the prediction software selected (Targetscan, MiRBase, PicTar and an exact seed search: $2-7$ or 1-8 first nucleotides of the miRNA), in each of the three 
categories. Enrichment in miRNA targets in each category is then tested using the hypergeometric function. Data obtained with MicroTopTable have been compared with the 'Sylamer' approach ${ }^{8}$ that confirmed overrepresentation of the same hexamers in our data set.

SDH assay. SDH activity was measured according to Gimenez-Roqueplo et al. ${ }^{27}$ Cellular lysates were diluted to $0.2 \mathrm{mg}$ protein $/ \mathrm{ml}$ in $50 \mathrm{mM}$ potassium phosphate buffer and pH 7.5 on ice. Sodium succinate $(20 \mathrm{mM})$, 2,6-dichloroindophenol $(50 \mu \mathrm{M})$, ATP $(100 \mu \mathrm{M})$ and potassium cyanide $(1 \mathrm{mM})$ were added to a well of a 96-well plate. The cellular lysate $(20 \mu \mathrm{l})$ containing $4 \mu \mathrm{g}$ of protein was added to the well and the reaction was started by addition of $50 \mu \mathrm{l}$ decylubiquinone $(0.4 \mathrm{mM})$. The decrease in absorbance at $600 \mathrm{~nm}$ was measured for $20 \mathrm{~min}$ at $37^{\circ} \mathrm{C}$. SDH activity was expressed as $\mathrm{mmol} / \mathrm{min} / \mathrm{mg}$.

Flow cytometric analysis of mitochondrial membrane potential. Changes in the $\Delta \psi \mathrm{m}$ were analyzed using the MitoProbe JC-1 assay kit (JC-1; Molecular Probes Inc., Eugene, OR, USA). This cyanine dye accumulates in the mitochondrial matrix under the influence of the $\Delta \psi \mathrm{m}$ and forms $J$ aggregates indicated by a fluorescence emission shift from green $(\sim 529 \mathrm{~nm})$ to red $(\sim 590 \mathrm{~nm})$. A549 cells transfected as described above were collected each indicated day and stained with $2 \mu \mathrm{M}$ of $\mathrm{JC}-1$ in warm medium at $1 \times 10^{6} \mathrm{cells} / \mathrm{ml}$ during $30 \mathrm{~min}$ at $37^{\circ} \mathrm{C}$. The cells were washed by adding $2 \mathrm{ml}$ of warm PBS, centrifugated and resuspended in $500 \mu \mathrm{l}$ PBS. As a positive control for reduction of $\Delta \psi \mathrm{m}$, A549 cells were treated with the uncoupling agent carbonyl cyanide $m$-chlorophenylhydrazone. Cell suspensions were prepared and flow cytometry was performed on a FACScalibur and analyzed using Cell quest (Becton-Dickinson Immunocytochemistry Systems, Le Pont de Claix, France). The ratio of green versus red fluorescence intensities was calculated.

Promoter reporter assay. Reverse transfection into A549 cells $\left(2 \times 10^{4}\right.$ cell per well) was made in triplicate with $100 \mathrm{ng}$ of a mixture of a transcription factorresponsive firefly luciferase construct 'E2F, p53 or HIF Reporter' (Cignal Finder Pathway Reporter Assays, SABiosciences, Frederick, MD, USA) and constitutively expressing Renilla luciferase construct $(40: 1)$ and $10 \mathrm{nM}$ of miRNA or siRNA by Lipofectamine 2000 (Invitrogen). A mixture of non-inducible firefly luciferase construct and constitutively expressing Renilla luciferase construct used as negative control and a mixture of constitutively expressing firefly and Renilla luciferase constructs used as positive control were also transfected. At $16 \mathrm{hh}$ after transfection, fresh medium with antibiotics was added, and 3-4 days later, the activities of the signaling pathway E2F, p53 or HIF was measured with the Dual-Glo luciferase assay (Promega).

Determination of the extracellular lactate concentration. The lactate concentration in the supernatant of cells incubated either in normoxia or in hypoxia of $1 \% \mathrm{O}_{2}$ for $48 \mathrm{~h}$ was determined by an enzyme-based assay using $900 \mu \mathrm{M} \beta$-NAD (BioChemika, Sigma-Aldrich, Lyon, France), $175 \mu \mathrm{g} / \mathrm{ml}$ L-lactate dehydrogenase (BioChemika) and $100 \mu \mathrm{g} / \mathrm{ml}$ glutamate--pyruvate transaminase (Roche) diluted in a sodium carbonate $(620 \mathrm{mM})$-L-gultamate $(79 \mathrm{mM})$ buffer adjusted to $\mathrm{pH} 10$. Lithium lactate was used as a standard. Measurement was done with a microplate reader after incubation for $30 \mathrm{~min}$ at $37^{\circ} \mathrm{C}$. For each condition, the protein concentration was determined to express the lactate concentration as $\mathrm{mM}$ / $\mu \mathrm{g}$ protein.

Colony assays. Following transfection, A549 cells were placed in normoxia or hypoxia $\left(1 \% \mathrm{O}_{2}\right)$ for $72 \mathrm{~h}$. Cells were then trypsinized, counted, re-plated at a density of 100 and 500 cells per well $\left(2.5 \mathrm{~cm}^{2}\right)$ and incubated during 11 days. Cells were then washed, fixed and stained. Images were background-subtracted and processed in ImageJ (http://rsbweb.nih.gov/ij) for CFU quantification. The surviving fractions were calculated based upon the plating efficiency.

Statistical analysis. Results are given as the mean \pm S.E.M. Statistical analysis was performed using the Student's t-test as provided by Microsoft Excel and the null hypothesis was rejected at the 0.05 level $\left({ }^{\star * *} P<0.0005,{ }^{* *} P<0.005\right.$, $\left.{ }^{*} P<0.05\right)$.

\section{Conflict of interest}

The authors declare no conflict of interest.
Acknowledgements. We acknowledge the excellent support of the NiceSophia Antipolis Functional Genomics Platform and of the 'Centre Commun de Microscopie Appliquée' from the University of Nice-Sophia-Antipolis. We thank Fredéric Brau and Julie Cazareth (Imaging Platform of IPMC, Sophia-Antipolis), Nicolas Pons (IPMC) and Karine IIc (Centre Antoine Lacassagne, Nice) for excellent technical assistance concerning microscopy, flow cytometry experiments and IHC. We acknowledge $\operatorname{Pr}$ Mouroux and $\operatorname{Pr}$ Vénissac (Department of Thoracic Surgery, Pasteur Hospital, $\mathrm{CHU}$ of Nice, France) for providing us with surgical lung specimens, and Mr Eric Selva and Ms Virginie Tanga-Gavric (Human Biobank, CHU of Nice) for excellent technical assistance. We thank Patrick Auberger, Brice Marcet and Patricia LM Dahia for helpful discussion and Ms Christiane Brahimi-Horn for critical reading and editorial correction of the paper. This work was supported by the Association pour la Recherche contre le Cancer (ARC post-doctoral Fellowship to MPP and Grant no. 1122 to JER), Cancéropole PACA (PB, PH and BM), INCa (PL0079, PB), European Community's Seventh Framework Program FP7/2007-2011 under grant agreement number 201279 (to KR, KL, SF, PB and BM) and METOXIA FP7 (to NMM and JP), and PHRC Grant 2003 CHU Nice (to BM, PB, KL, VH and PH).

1. Harpole DH Jr. Prognostic modeling in early stage lung cancer: an evolving process from histopathology to genomics. Thorac Surg Clin 2007; 17: 167-173, viii.

2. Lu J, Getz G, Miska EA, Alvarez-Saavedra E, Lamb J, Peck D et al. MicroRNA expression profiles classify human cancers. Nature 2005; 435: 834-838.

3. Volinia S, Calin GA, Liu CG, Ambs S, Cimmino A, Petrocca F et al. A microRNA expression signature of human solid tumors defines cancer gene targets. Proc Natl Acad Sci USA 2006; 103: 2257-2261.

4. Ortholan C, Puissegur MP, llie M, Barbry P, Mari B, Hofman P. MicroRNAs and lung cancer: new oncogenes and tumor suppressors, new prognostic factors and potential therapeutic targets. Curr Med Chem 2009; 16: 1047-1061.

5. Bartel DP. MicroRNAs: target recognition and regulatory functions. Cell 2009; 136: 215-233.

6. Grimson A, Farh KK, Johnston WK, Garrett-Engele P, Lim LP, Bartel DP. MicroRNA targeting specificity in mammals: determinants beyond seed pairing. Mol Cell 2007; 27: 91-105.

7. Lim LP, Lau NC, Garrett-Engele P, Grimson A, Schelter JM, Castle J et al. Microarray analysis shows that some microRNAs downregulate large numbers of target mRNAs. Nature 2005; 433: 769-773.

8. van Dongen S, Abreu-Goodger C, Enright AJ. Detecting microRNA binding and siRNA off-target effects from expression data. Nat Methods 2008; 5: 1023-1025.

9. Pottier N, Maurin T, Chevalier B, Puissegur MP, Lebrigand K, Robbe-Sermesant K et al. Identification of keratinocyte growth factor as a target of microRNA-155 in lung fibroblasts: implication in epithelial-mesenchymal interactions. PLoS One 2009; 4: e6718.

10. Camps C, Buffa FM, Colella S, Moore J, Sotiriou C, Sheldon H et al. hsa-miR-210 is induced by hypoxia and is an independent prognostic factor in breast cancer. Clin Cancer Res 2008; 14: 1340-1348.

11. Giannakakis A, Sandaltzopoulos R, Greshock J, Liang S, Huang J, Hasegawa K et al. miR-210 links hypoxia with cell cycle regulation and is deleted in human epithelial ovarian cancer. Cancer Biol Ther 2008; 7: 255-264.

12. Huang X, Ding L, Bennewith KL, Tong RT, Welford SM, Ang KK et al. Hypoxia-inducible mir-210 regulates normoxic gene expression involved in tumor initiation. Mol Cell 2009; 35 : 856-867.

13. Foekens JA, Sieuwerts AM, Smid M, Look MP, de Weerd V, Boersma AW et al. Four miRNAs associated with aggressiveness of lymph node-negative, estrogen receptorpositive human breast cancer. Proc Natl Acad Sci USA 2008; 105: 13021-13026.

14. Greither T, Grochola LF, Udelnow A, Lautenschlager C, Wurl P, Taubert H. Elevated expression of microRNAs 155, 203, 210 and 222 in pancreatic tumors is associated with poorer survival. Int J Cancer 2009; 126: 73-80.

15. Zhang Z, Sun H, Dai H, Walsh RM, Imakura M, Schelter J et al. MicroRNA miR-210 modulates cellular response to hypoxia through the MYC antagonist MNT. Cell Cycle 2009; 8: $2756-2768$

16. Kulshreshtha R, Ferracin M, Wojcik SE, Garzon R, Alder H, Agosto-Perez FJ et al. A microRNA signature of hypoxia. Mol Cell Biol 2007; 27: 1859-1867.

17. Fasanaro $P$, D’Alessandra $Y$, Di Stefano V, Melchionna R, Romani S, Pompilio G et al. MicroRNA-210 modulates endothelial cell response to hypoxia and inhibits the receptor tyrosine kinase ligand Ephrin-A3. J Biol Chem 2008; 283: 15878-15883.

18. Chan SY, Zhang YY, Hemann C, Mahoney CE, Zweier JL, Loscalzo J. MicroRNA-210 controls mitochondrial metabolism during hypoxia by repressing the iron-sulfur cluster assembly proteins ISCU1/2. Cell Metab 2009; 10: 273-284.

19. Triboulet R, Mari B, Lin YL, Chable-Bessia C, Bennasser Y, Lebrigand K et al. Suppression of microRNA-silencing pathway by HIV-1 during virus replication. Science 2007; 315: 1579-1582.

20. Yanaihara N, Caplen N, Bowman E, Seike M, Kumamoto K, Yi M et al. Unique microRNA molecular profiles in lung cancer diagnosis and prognosis. Cancer Cell 2006; 9: 189-198.

21. Giatromanolaki A, Koukourakis MI, Sivridis E, Pastorek J, Wykoff CC, Gatter KC et al. Expression of hypoxia-inducible carbonic anhydrase-9 relates to angiogenic pathways and independently to poor outcome in non-small cell lung cancer. Cancer Res 2001; 61: 7992-7998. 
22. Ilie M, Mazure NM, Hofman V, Ammadi RE, Ortholan C, Bonnetaud $\mathrm{C}$ et al. High levels of carbonic anhydrase IX in tumour tissue and plasma are biomarkers of poor prognostic in patients with non-small cell lung cancer. Br J Cancer 2010; 102: 1627-1635.

23. Buffa FM, Harris AL, West CM, Miller CJ. Large meta-analysis of multiple cancers reveals a common, compact and highly prognostic hypoxia metagene. Br J Cancer 2010; 102: 428-435.

24. Favaro E, Ramachandran A, McCormick R, Gee H, Blancher $\mathrm{C}$, Crosby $\mathrm{M}$ et al. MicroRNA210 regulates mitochondrial free radical response to hypoxia and krebs cycle in cancer cells by targeting iron sulfur cluster protein ISCU. PLoS One 2010; 5: e10345.

25. Tazawa $H$, Tsuchiya N, Izumiya $M$, Nakagama $H$. Tumor-suppressive miR-34a induces senescence-like growth arrest through modulation of the E2F pathway in human colon cancer cells. Proc Natl Acad Sci USA 2007; 104: 15472-15477.

26. Le Brigand K, Russell R, Moreilhon C, Rouillard JM, Jost B, Amiot F et al. An open-access long oligonucleotide microarray resource for analysis of the human and mouse transcriptomes. Nucleic Acids Res 2006; 34: e87.

27. Gimenez-Roqueplo AP, Favier J, Rustin P, Mourad JJ, Plouin PF, Corvol P et al. The R22X mutation of the SDHD gene in hereditary paraganglioma abolishes the enzymatic activity of complex II in the mitochondrial respiratory chain and activates the hypoxia pathway. Am J Hum Genet 2001; 69: 1186-1197.

28. Dahia PL, Ross KN, Wright ME, Hayashida CY, Santagata S, Barontini M et al. A HIF1alpha regulatory loop links hypoxia and mitochondrial signals in pheochromocytomas. PLoS Genet 2005; 1: 72-80.

29. Fasanaro $P$, Greco $S$, Lorenzi M, Pescatori M, Brioschi M, Kulshreshtha $R$ et al. An integrated approach for experimental target identification of hypoxia-induced miR-210. J Biol Chem 2009; 284: 35134-35143.
30. Gottlieb E, Tomlinson IP. Mitochondrial tumour suppressors: a genetic and biochemical update. Nat Rev Cancer 2005; 5: 857-866.

31. Chen Z, Li Y, Zhang H, Huang P, Luthra R. Hypoxia-regulated microRNA-210 modulates mitochondrial function and decreases ISCU and COX10 expression. Oncogene 2010; 29 4362-4368.

32. Semenza GL. Oxygen-dependent regulation of mitochondrial respiration by hypoxiainducible factor 1. Biochem J 2007; 405: 1-9.

33. Kulshreshtha R, Davuluri RV, Calin GA, Ivan M. A microRNA component of the hypoxic response. Cell Death Differ 2008; 15: 667-671.

34. Denko NC. Hypoxia, HIF1 and glucose metabolism in the solid tumour. Nat Rev Cancer 2008; 8: 705-713.

35. King A, Selak MA, Gottlieb E. Succinate dehydrogenase and fumarate hydratase: linking mitochondrial dysfunction and cancer. Oncogene 2006; 25: 4675-4682.

36. Kaelin WG. The von Hippel-Lindau tumor suppressor protein: roles in cancer and oxygen sensing. Cold Spring Harb Symp Quant Biol 2005; 70: 159-166.

37. Selak MA, Armour SM, MacKenzie ED, Boulahbel H, Watson DG, Mansfield KD et al. Succinate links TCA cycle dysfunction to oncogenesis by inhibiting HIF-alpha prolyl hydroxylase. Cancer Cell 2005; 7: 77-85.

38. Richard DE, Berra E, Gothie E, Roux D, Pouyssegur J. p42/p44 mitogen-activated protein kinases phosphorylate hypoxia-inducible factor 1alpha (HIF-1alpha) and enhance the transcriptional activity of HIF-1. J Biol Chem 1999; 274: 32631-32637.

39. Griffiths-Jones S. miRBase: the microRNA sequence database. Methods Mol Biol 2006; 342: $129-138$.

40. Le Brigand K, Barbry P. Mediante: a web-based microarray data manager. Bioinformatics 2007: 23: 1304-1306.

\section{Supplementary Information accompanies the paper on Cell Death and Differentiation website (http://www.nature.com/cdd)}

